\title{
Designed Antitumor Peptide for Targeted siRNA Delivery into Cancer Spheroids
}

\author{
Silvia Cirillo, Mhd Anas Tomeh, Robert N Wilkinson, Chris Hill, Stephen Brown,* and Xiubo Zhao* \\ Cite This: ACS Appl. Mater. Interfaces 2021, 13, 49713-49728 \\ Read Online
}

ABSTRACT: Antimicrobial/anticancer peptides (AMPs/ACPs) have shown promising results as new therapeutic agents in cancer thearpy. Among them, the designed amphiphilic $\alpha$-helical peptide G(IIKK) ${ }_{3} \mathrm{I}$ $\mathrm{NH}_{2}$ (G3) displayed great affinity and specificity in targeting cancer cells. Here, we report new insights on how G3 penetrates cancer cells. G3 showed high specificity to HCT-116 colon cancer cells compared to the HDFs (human neonatal primary dermal fibroblasts) control. With high concentrations of peptide, a clear cancer cell membrane disruption was observed through SEM. Gene knockdown of the endocytic pathways demonstrated that an energy-dependent endocytic pathway is required for the uptake of the peptide. In addition, G3 can protect and selectively deliver siRNAs into cancer cells and successfully modulated their gene expression. Gene delivery was also tested in 3D cancer spheroids and showed deep penetration delivery into the cancer spheroids. Finally, the in vivo toxicity of G3 was evaluated on zebrafish embryos, showing an increasing toxicity effect with concentration. However, the toxicity of the peptide was attenuated when complexed

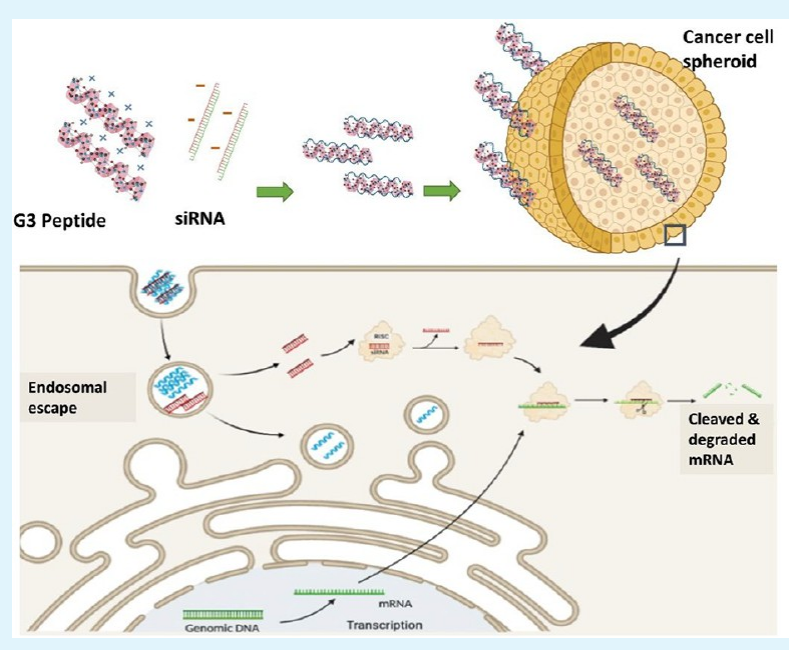
with siRNA. In addition, negligible toxicity was observed at the concentration range for efficient gene delivery. The current results demonstrate that G3 is promising as an excellent agent for cancer therapy.

KEYWORDS: antimicrobial/anticancer peptides, siRNA delivery, gene knockdown, endocytic pathway, RNAi screening

\section{INTRODUCTION}

Cancer is one of the biggest threats to human life. The current cancer treatment strategies (such as surgery, chemotherapy, and radiotherapy) are often ineffective and can potentially induce severe life-threatening side effects. The lack of cell specificity for chemotherapy is often the main cause for a poor outcome. ${ }^{1,2}$ In recent years, novel cancer therapies have been proposed to improve cell specificity and consequently reduce adverse effects. Gene therapy is one of the most promising methods for many cancers due to the defective gene expression in tumor cells. However, genetic materials often have difficulty passing the biological barriers, in order to reach the appropriate intracellular targets. $^{3}$ Over the years, many approaches (both viral and nonviral systems) have been trialled to develop effective gene delivery systems. ${ }^{4-9}$ However, their effectiveness and specificity are still to be improved.

One of the promising classes of materials for drug/gene delivery is antimicrobial peptides (AMPs), which has a wide spectrum of activity not only to pathogens but also to cancer cells. Therefore, AMPs are the perfect candidates to be employed as potential new therapeutic and delivery agents. ${ }^{10,11}$ Most of the AMPs fall in two groups: $\alpha$-helical and $\beta$-sheet peptides. $\alpha$-helical AMPs are the most abundant and broadly studied. They are generally linear with net positive charges (between +2 and +9 ) from amino acids such as lysine $(\mathrm{K})$, arginine $(\mathrm{R})$, and histidine $(\mathrm{H})$, a considerable quantity of hydrophobic residues $(\geq 30 \%)$ such as valine $(V)$, leucine $(L)$, isoleucine (I), phenylalanine (F), and tryptophan (W), a welldefined amphipathicity, and a generally small size (normally 650 residues long). ${ }^{12,13}$ To reduce the toxicity toward host cells, these peptides often exist in aqueous solution as unstructured monomers, folding into $\alpha$-helical structures when in contact with negatively charged lipid membranes. ${ }^{14,15}$ This structure propensity is critical for antimicrobial activity and to lower down cytotoxicity toward host cells. ${ }^{16}$ AMPs with anticancer properties are often referred as anticancer peptides (ACPs). ${ }^{10}$ The current anticancer drugs are based on alkylating agents, alkaloids or antimetabolites, and not only have poor cell selectivity but also often are deactivated by the cancer cells' intrinsic resistance

Received: August 3, 2021

Accepted: September 28, 2021

Published: October 18, 2021 
mechanisms, which rapidly remove them from the cytosol before they can exerting their actions on the designed intracellular targets. ${ }^{17}$ In contrast, ACPs show a much better cell selectivity and reduced resistance, therefore, have been increasingly studied as possible novel therapeutics. ${ }^{17}$ To improve the cell specificity and the drug delivery efficiency, new peptide based delivery systems have been developed using cell penetrating peptides (CPPs) or more specifically tumor targeting peptides (TPPs). ${ }^{18}$

$\mathrm{G}(\mathrm{IIKK})_{3} \mathrm{I}-\mathrm{NH}_{2}$ (G3) is a member of a class of synthetic short cationic amphiphilic peptides $\mathrm{G}(\mathrm{IIKK})_{n} \mathrm{I}-\mathrm{NH}_{2}(n=1-4)$ containing the repeated sequence IIKK (or IKKI), which enables the ratio of hydrophobic isoleucine (I) to cationic lysine (K) residues remaining equal. ${ }^{19}$ Similar to others $\alpha$-helical peptides, G3 remains unfolded in aqueous solution. However, when interact with the negatively charged DPPG $(1,2-$ dipalmitoylsn-glycero-3-phosphoglycerol) small unilamellar vesicles (SUVs), which mimic bacterial and tumor cell membranes, it adopts the typical $\alpha$-helical structure. ${ }^{19-21}$ Previous studies revealed that G3 has excellent antibacterial activity against both Gram-positive (Bacillus subtilis, Staphylococcus aureus, and MRSA) and Gram-negative (Escherichia coli and Pseudomonas aeruginosa) but at the same time low cytotoxicity toward mammalian host. ${ }^{19-22}$ Recent research also showed that G3 has cancer cell selectivity with a possible cytostatic effect against $\mathrm{HeLa}$ and promyelocytic leukemia HL60 and an in vivo growth inhibitory effect on HeLa cells xenografts in nude mice inducing only a little toxicity to the murine hosts. ${ }^{23}$ Therefore, it has been increasingly studied for antimicrobial and anticancer applications.

In this work, using its cancer cell targeting and membrane disruption effects, G3 has been explored to be used as the siRNA delivery carriers. An in-depth investigation was performed to evaluate the selectivity of G3 peptide toward human cancer and non-cancer cells, using HCT-116 (colon cancer cells) as a cancer cell model and HDFs (human neonatal primary dermal fibroblasts) as a non-cancer model. The uptake pathways of the G3 into cancer cells were systematically studied. G3 was subsequently used to transfect siRNA in $2 \mathrm{D}$ cell cultures and in 3D tumor spheroid models. The ability of G3 to function as a delivery vector for knockdown of ECT2 and PLK1, cancerrelated genes, was also assessed. The results demonstrate that an energy-dependent pathway is necessary to internalize this peptide and the specific endocytic pathway which is used in the uptake was successfully identified using a high content RNAi screening. Finally, the peptide toxicity was evaluated in vivo on zebrafish embryos monitoring the animals' development over a period of 3 days. Complexes of peptide and siRNA were also injected in zebrafish to further investigate G3 toxicity. The current work highlights the efficacy of this small cationic peptide in targeting cancer cells and its promising future as a delivery agent in cancer therapies.

\section{MATERIALS AND METHODS}

2.1. Peptides Synthesis. The peptide G(IIKK) ${ }_{3} \mathrm{I}-\mathrm{NH}_{2}$ (G3) was synthesized using standard Fmoc solid-phase synthesis, from natural Lamino acids, on a commercial CEM Liberty microwave peptide synthesizer as described in previous publications. ${ }^{19,23-25}$ The Cterminal was amidated at the beginning of the synthesis using a Rinkamide MBHA resin, while the $\mathrm{N}$-terminal was capped with a glycine (G) prior cleavage from the resin. The final product was purified by cold ether precipitation (purity of $>95 \%$ ) as indicated by RP-HLPC and MS analyses. FITC-G(IIKK) ${ }_{3} \mathrm{I}-\mathrm{NH}_{2}$ (FITC-G3) was also synthesized using the same protocol. ${ }^{26}$ Stock solutions were prepared by dissolving the peptides in UHQ water and stored at $-20^{\circ} \mathrm{C}$.

2.2. Cell Culture. The human epithelial A431 cancer cells were obtained from the Centre for Membrane Interactions and Dynamics; the human HCT-116 colon cancer cells were obtained from the Department of Oncology \& Metabolism; and the primary human dermal fibroblasts (HDFs) were obtained from the Centre for Stem Cell Biology, all at the University of Sheffield. Cells were cultured in DMEM medium (GIBCO, Thermo Fisher Technologies) supplemented with $10 \%$ heat-inactivated fetal bovine serum (FBS) (Merck) and $100 \mathrm{U} / \mathrm{mL}$ penicillin and $100 \mu \mathrm{g} / \mathrm{mL}$ streptomycin (GIBCO, Thermo Fisher Scientific) at $37{ }^{\circ} \mathrm{C}$ and $5 \% \mathrm{CO}_{2}$. The cell lines were periodically tested for the presence of Mycoplasma with EZ-PCR Mycoplasma Test Kit (BI, Biological Industries) and authenticated by STR profiling using the PowerPlex 16 HS PCR amplification kit (Promega)

2.3. Cell Counting Viability Assay. To evaluate the effect of G3 and FITC-G3 against mammalian cells, the cell counting viability assay was performed. Briefly, HCT-116 or HDF cells were seeded in a 96 well plate (Corning) at variable densities, depending on the exposure times or the cell type, in $90 \mu \mathrm{L}$ of complete culture medium and incubated at $37{ }^{\circ} \mathrm{C}$. On the following day, $10 \mu \mathrm{L}$ aliquots of peptide at different concentrations $(6.25-100 \mu \mathrm{M})$ were added to the wells and incubated for further 24,48 , or $72 \mathrm{~h} . \mathrm{Na}_{2} \mathrm{CrO}_{4}$ (Sodium chromate tetrahydrate, CAS number: 10034-82-91, Merck) was used as a positive control at $200 \mu \mathrm{M}$, while the negative control was represented by the UHQ water. Cells were fixed in $4 \%$ paraformaldehyde solution (Merck) and stained with $2 \mu \mathrm{g} / \mathrm{mL}$ Hoechst 33342 (Thermo Fisher).

2.4. Cell Selectivity Assay. HCT-116 and HDFs were exposed to several concentrations of FITC-G3 for $24 \mathrm{~h}$ and washed with an acid buffer ( $50 \mathrm{mM}$ glycine- $\mathrm{HCl}, 2 \mathrm{M}$ urea, and $100 \mathrm{mM} \mathrm{NaCl}, \mathrm{pH} 3$ ) prior to fixation with $4 \%$ paraformaldehyde solution. Hoechst $33342(2 \mu \mathrm{g} /$ $\mathrm{mL})$ (blue) was used as nuclear staining, while Cell Mask Orange ( $0.1 \times$ of working solution) was used as plasma membranes staining (red).

2.5. Cold Assay Experiment. HCT-116 cells were seeded in six well plates (Corning) at $8 \times 10^{5}$ cells/well and incubated overnight at $37^{\circ} \mathrm{C}$. On the following day, the medium was removed, and the cells were washed twice in cold PBS $\left(4{ }^{\circ} \mathrm{C}\right)$ to block endocytosis. Cold complete growth medium was added to the wells together with $12.5 \mu \mathrm{M}$ FITC-G3. Plates were then left for $30 \mathrm{~min}$ in ice. The cells were washed in cold PBS. Some cells were instead moved back into the incubator at $37^{\circ} \mathrm{C}$ for further $3 \mathrm{~h}$. In addition, two different conditions were set up: cells kept in the original medium containing the peptide, or cells were washed and incubated with new warm medium but lacking peptide. Controls were prepared as follows: peptide at the same concentration was added to cells which were then incubated at $37^{\circ} \mathrm{C}$ for $30 \mathrm{~min}$ or $3 \mathrm{~h}$. Autofluorescence was detected and subtracted from the background level using untreated cells. All the cells were fixed and stained in a $4 \%$ paraformaldehyde and $2 \mu \mathrm{g} / \mathrm{mL}$ Hoechst 33342 solution.

2.6. siRNA Transfection Procedure. G3 or FITC-G3 peptides were complexed in complete culture medium with siRNA molecules at different cationic/anionic charge (molar) ratios. The commercial red fluorescent siRNA (siGLO Red Transfection Indicator, Dharmacon), or the targeting PLK1 and ECT2 siRNAs (ON-TARGETplus, Dharmacon) were used in the siRNA delivery experiments. siRNA and peptide concentrations varied between 30 and $75 \mathrm{nM}$, depending on the assay, while complexes were prepared with charge ratios between 0.5:1 and 10:1. DharmaFECT1 (Dharmacon) was used as the positive control for transfection following the manufacturer's instruction. Wells with only siRNA addition were prepared as the negative control.

2.7. Cancer Cells Targeting Experiment. HCT-116 and HDF cells were co-cultured together and transfected with $50 \mathrm{nM}$ of siGLO using DharmaFECT1 or G3, at different ratios. Briefly, $5 \times 10^{3} \mathrm{HCT}$ 116 and $2 \times 10^{4} \mathrm{HDFs}$ cells were seeded on a 96 wells plate. Peptide/ siGLO complexes were then added to the wells. On the next day, the plate was fixed in $4 \%$ paraformaldehyde and stained with Hoechst 33342 .

2.8. 3D Spheroids Transfection. A431 and HCT-116 3D spheroids were prepared for 3D transfection. Briefly, cells were seeded in round low attachment 96 well plates at a density of $1 \times 10^{4}$ cells/well 
(a)

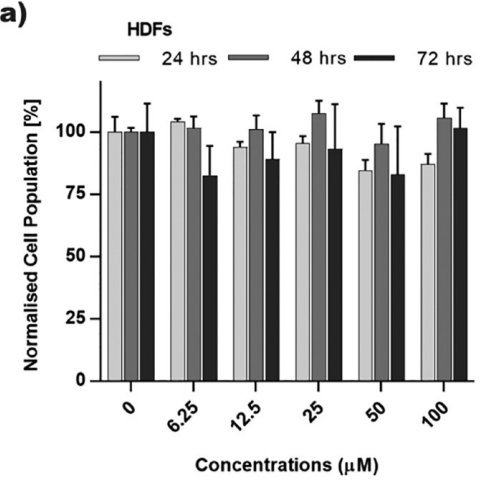

(b)

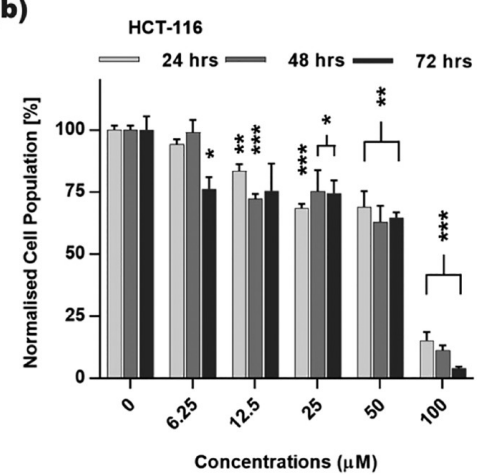

Figure 1. High content cell counting assay to evaluate the impact of G3 peptide on non-cancer and cancer models. Number of (a) HDFs (human dermal fibroblasts) or (b) HCT-116 (colon cancer cells) counted after exposure to increasing concentration of G3 peptide for 24-72 h, normalized to the relative negative control and expressed as a percentage. The values obtained are averages of independent experiments with at least three replicates for each experimental point \pm standard error mean $( \pm \mathrm{SEM}) . \mathrm{Na}_{2} \mathrm{CrO}_{4}(200 \mu \mathrm{M})$ was used as a positive control (data not showed), while water was used as negative control (0). Statistically significant differences from the negative controls were determined by Student's $t$ test $\left({ }^{*} \mathrm{p}<0.05 ;{ }^{*} \mathrm{p}<0.01\right.$; $* * * \mathrm{p}<0.001)$.

in complete medium and grown for $48 \mathrm{~h}$ at $37^{\circ} \mathrm{C}$. Using $\mathrm{G} 3$ peptide or DharmaFECT1, $75 \mathrm{nM}$ siGLO were then transfected into each spheroid using various ratios of peptide/siRNA (from 0.5:1 to 5:1). On the next day, the spheroids were fixed in $4 \%$ paraformaldehyde solution and stained with Hoechst 33342 solution before being observed under the light-sheet microscope.

2.9. Sample Preparation for Scanning and Transmission Electron Microscopy. For scanning electron microscopy (SEM), HCT-116 cells were seeded in 12 well plates on glass coverslips at a density of $3 \times 10^{5}$ cells/well in complete medium and grown for $24 \mathrm{~h}$ at $37^{\circ} \mathrm{C}$. On the next day, cells were exposed to different concentrations of FITC-G3 $(0.3,6.25$, and $100 \mu \mathrm{M})$ for $24 \mathrm{~h}$. An untreated control was prepared as well. Samples were fixed with $3 \%$ Glutaraldehyde (Merck) in 0.1 M Sodium Cacodylate (Merck) buffer ( $\mathrm{pH} 7.4$ ) before being rinsed in the cacodylate buffer and postfixed using $2 \%$ aqueous osmium tetroxide (Merck). Following ethanol and hexamethyldisilazane (HEX) (Merck) dehydration, samples were dried overnight in 100\% ethanol and examined using a Philips XL-20 SEM at $15 \mathrm{kV}$. For transmission electron microscopy (TEM), a mouse monoclonal antibody anti-FITC labeled with $10 \mathrm{~nm}$ gold nanoparticles was used (Aurion, Cat. No. 25583). Briefly, HCT-116 cells were seeded in a 96 well plate at the density of $2 \times 10^{4}$ cells per well in complete culture medium and incubated overnight at $37^{\circ} \mathrm{C}$. After 1 day of attachment, the cells were treated with $6.25 \mu \mathrm{M}$ of FITC-G3, complexed with the mouse monoclonal antibody anti-FITC at 1/100 dilution and then added to cells for either 3 or $24 \mathrm{~h}$. The samples were fixed as a pellet in $4 \%$ paraformaldehyde solution, followed by ethanol dehydration in proportion 50:50 with the acrylic LR white resin. The samples were embedded in fresh LR white resin and put in polyethylene capsules (TAAB, Cat. No. C094). An alternative fixation method was performed on some samples, to enhance cellular contrast and reduce image darkness. In this case, samples were fixed using $3 \%$ glutaraldehyde in 0.1 $\mathrm{M}$ sodium cacodylate buffer ( $\mathrm{pH}$ 7.4) then washed in the same buffer and postfixed with $2 \%$ osmium tetroxide. Samples were then dehydrated with ethanol, cleared in epoxypropane (EPP) (CAS Number 16088-62-3, Merck), infiltrated in 50:50 Araldite resin and EPP mixture and embedded. Ultrathin sections of approximately $85 \mathrm{~nm}$ thick were cut on a Leica UC 6 ultramicrotome and stained with uranyl acetate followed by Reynold's Lead Citrate. Sections were examined using a FEI Tecnai transmission electron microscope at $80 \mathrm{kV}$.

2.10. RNAi Screen. HCT-116 cells $\left(2 \times 10^{3}\right.$ cells/well $)$ were seeded in 384 well plates and were reverse transfected with $30 \mathrm{nM}$ of siRNAs using DharmaFECT1. After 3 days, cells were exposed to $6.25 \mu \mathrm{M}$ of FITC-G3 peptide and incubated further $24 \mathrm{~h}$. Cells were fixed in $4 \%$ paraformaldehyde solution and stained with $2 \mu \mathrm{g} / \mathrm{mL}$ Hoechst 33342 solution. Images were acquired with the fluorescent automated widefield high-content microscope. The difference in fluorescent intensity across the plate was analyzed and the data obtained were subsequently used to calculate the robust $\mathrm{Z}$ score of each silenced gene.

A library of siRNAs assay (Supporting Information (SI) Table S1) development plate 2 (ASD2), specifically designed for genome-wide RNAi screens, was used for the initial development screen. The plate used for the focused larger screen instead, was a specific library (SI Table S2) of Traffic-ome targeting siRNAs designed by Doctor Andrew Peden and Professor Elizabeth Smythe (Biomedical Science Department, Sheffield University).

2.11. Zebrafish Husbandry and Strain. Zebrafish were raised in the Bateson Centre aquaria (University of Sheffield), fed with Artemia nauplii and maintained in recirculating system at $28{ }^{\circ} \mathrm{C}$ on a constant 14:10 $\mathrm{h}$ light cycle. The studies performed on zebrafish and described in these pages are conformed with the UK Home Office regulations and under the project license: 40/3408 held by RNW. Embryos were exclusively obtained from natural spawning and raised at $28{ }^{\circ} \mathrm{C}$.

2.12. Microinjections in Zebrafish Embryos. FITC-G3 peptide, siGLO red fluorescent siRNA or peptide/siGLO complexes were injected in 1-cell stage embryos. The peptide was injected in a range between $6.25 \mathrm{pg}$ and $4 \mathrm{ng}$ per embryo; the fluorescent siRNA was injected in a concentration range of $20-80$ pg per embryo, while the complexes were made with $20 \mathrm{pg}$ of siGLO and 20 or $80 \mathrm{pg}$ of peptide per embryo. Several fish batches were used in each experiment and uninjected embryos were always kept as controls. On average, 80 eggs per concentration were injected. Live embryos were checked on a Leica MZ16 stereomicroscope at 1- or 3-days post fertilization (dpf) and the viability was recorded. Conforming to the UK Home Office regulation, before reaching $5.2 \mathrm{dpf}$ embryos were anaesthetised using Tricaine (40 $\mathrm{mg} / \mathrm{L}$ ) and sacrificed in a bleach solution.

2.13. Microscopy. Cell counting viability assays and the transfection outcomes of fluorescent experiments were all acquired using the fluorescent automated wide-field high-content ImageXpress Micro microscope (Molecular Device) and segmentation analysis performed using MetaXpress Software 5.3.01 (Molecular Devices). 3D spheroids images were acquired using the light sheet fluorescent microscope Zeiss Lightsheet Z.1 and analyzed with the ZEN 2014 SP1 (Zeiss) software. The cocultured cell system and the cold assay experiments were imaged using the IN Cell Analyzer 2200 (GE Healthcare) microscope. Quantification of peptide uptake following cold assay was performed using the In Cell Developer Toolbox 1.9 (GE Healthcare). Images of 3 dpf zebrafish embryos were acquired using a Zeiss Axio Zoom.V16 fluorescence stereomicroscope. ImageJ was used for further image processing.

\section{RESULTS}

3.1. In Vitro Cell Toxicity and Specificity. Previous studies on G3 showed excellent antimicrobial effect and a 
(a)
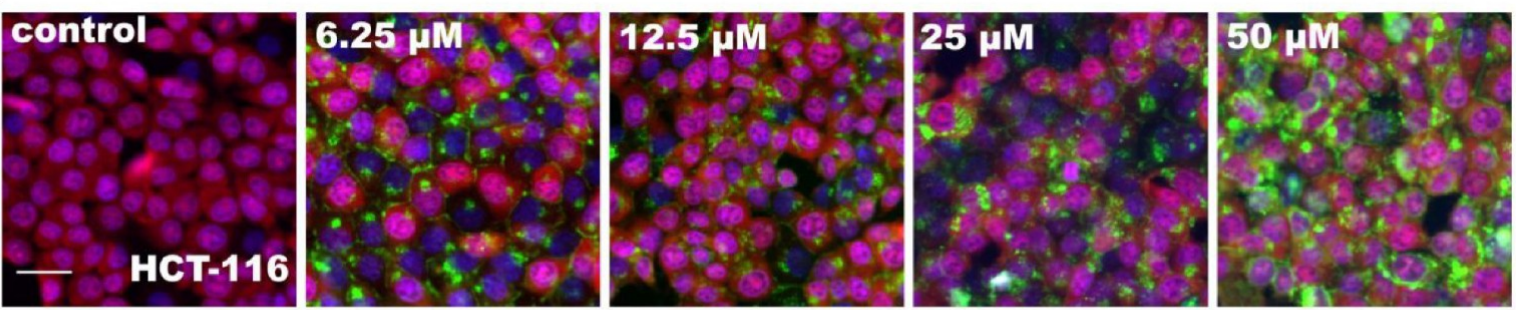

(b)
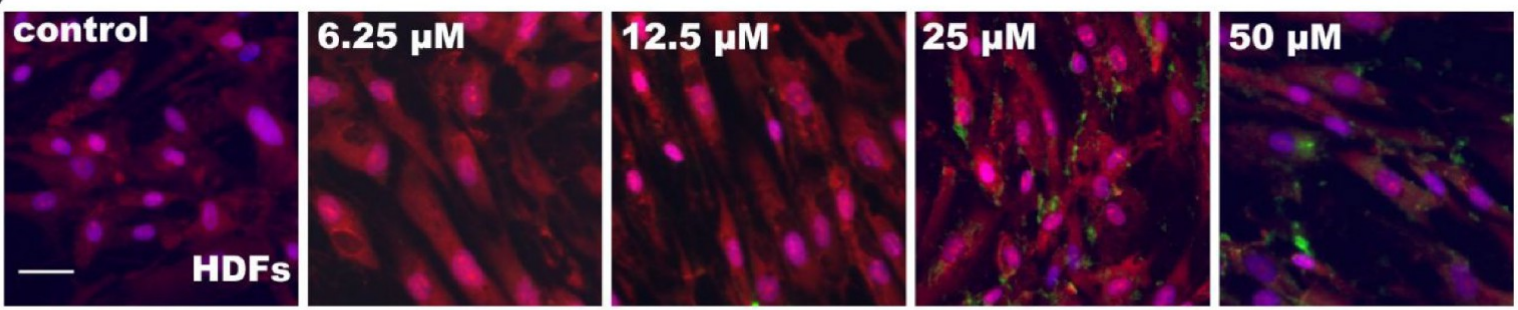

(c)

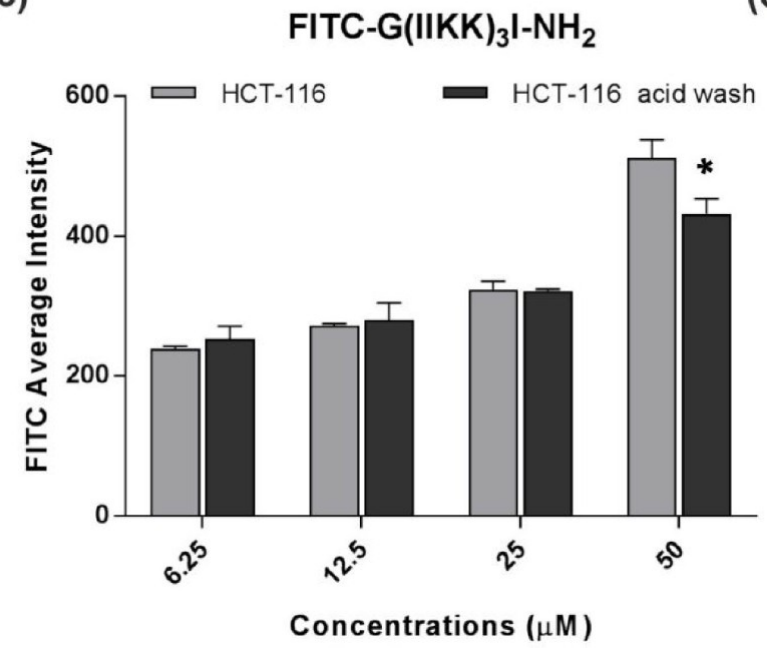

(d)

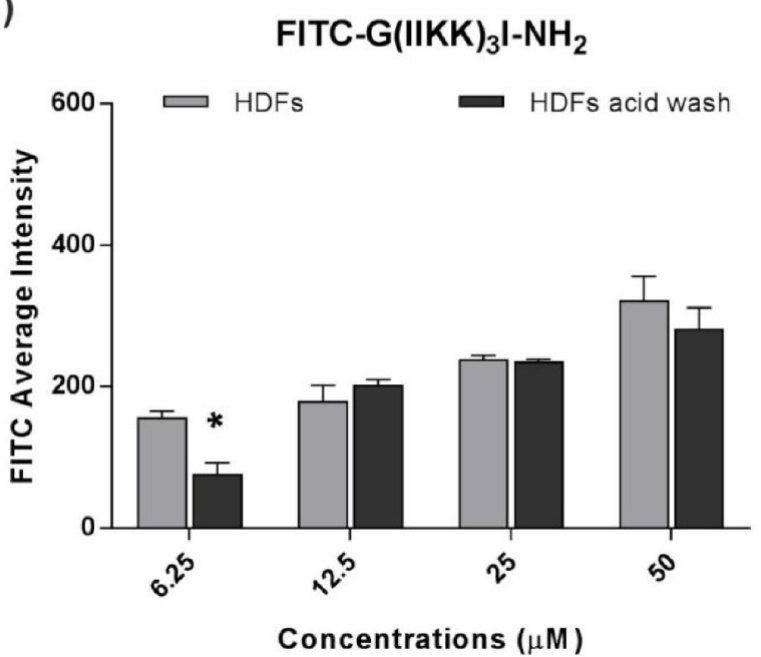

Figure 2. Cancer cell selectivity and concentration dependent peptide uptake assay. HCT-116 (a) and HDFs (b) were exposed to several concentrations of FITC-G3 for $24 \mathrm{~h}$ and washed with an acid buffer before fixation. The plasma membrane was stained by Cell Mask Orange (red) and the nuclei were stained by Hoechst 33342 (blue). The acid wash removes peptides bound to the cellular membranes and in this instance, therefore, can be used to evaluate the effective amount of peptides internalized into the cells. The peptide showed clear cancer cell selectivity and internalization. FITC intensity of HCT-116 (c) and HDF (d) cells before and after acid wash, indicating that peptides were inside the cells rather than on the cell membrane surface. Bar $=25 \mu \mathrm{m}$ and all the images are scaled at the same size. Statistically significant differences from the negative controls were determined by Student's $t$ test $(* p<0.05 ; * *<0.01 ; * * p<0.001)$.

tangible cytotoxic effect in multiple cancer cell lines (e.g., HeLa, HepG2, and HL60 cells) but still benign to normal cells such as dermal fibroblasts. ${ }^{19,22,23}$ In this study, its toxicity and specificity were first tested against HDFs and HCT-116, using the cell counting method. Changes in the total cell number, induced by reduced proliferation or increased cell death is a direct measure of cell viability. High content microscopy was used to count cells in each well of a 96 well plate where cells were exposed to different peptide concentrations and incubated over a period of 24-72 h. Figure 1a shows the results on primary HDFs. These results were consistent with the previous work, showing that G3 has very little impact on perturbing the growth of normal human mammalian cells, even at extremely high concentrations. ${ }^{19,22,23}$ Figure $1 \mathrm{~b}$ shows that exposure of G3 on HCT-116 resulted in a significant decrease in the number of cells, especially after $72 \mathrm{~h}$ and at the highest dose $(100 \mu \mathrm{M})$. In comparison, previous work using MTT assay showed a much greater grade of toxicity toward cancer cells, already visible after $24 \mathrm{~h}$ and at much lower doses than the ones tested in this assay. ${ }^{27-29}$ The uptake of the MTT salt in the cells can be variable and it often reflects a measure of the metabolic activity rather than the cell death. The difference between the two assays indicates that the peptide resulted in the cell cytostatic effect at lower peptide concentrations and at the early stage, while a much higher concentration is required to result in cell death. ${ }^{30}$ It is worth mentioning that the observed peptide toxicity toward HCT-116 cells at certain time points or concentrations is not the focus of this work, which instead is to assess the ability of G3 to carry siRNA molecules inside cancer cells. We have also evaluated the effect of $24 \mathrm{~h}$ exposure of FITC-G3 on HCT-116 and HDFs to determine whether the presence of the fluorophore could have had an impact on the peptide's intrinsic cell selectivity. The results (SI Figure S1) revealed that FITC-G3 behaved similarly to G3 apart from a slight increase of toxicity toward the normal 
(a)

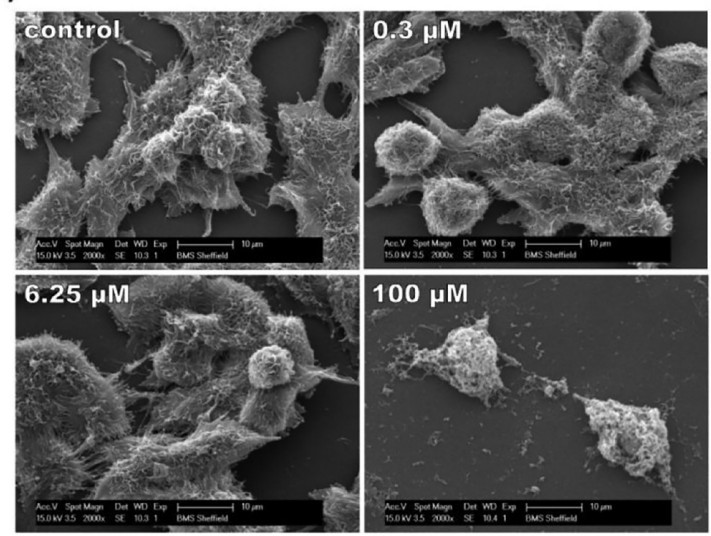

(b)

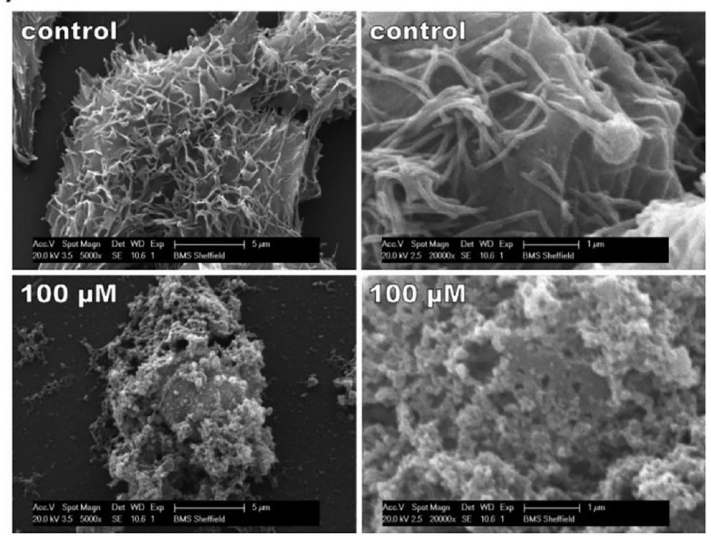

Figure 3. SEM images of peptide treated cancer cell surfaces. (a) HCT-116 cells were exposed to different concentrations $(0,0.3,6.25$, and $100 \mu \mathrm{M})$ of G3 peptide. Bars $=10 \mu \mathrm{m}$. (b) Magnified images of control cells (top) and $100 \mu \mathrm{M}$ peptide treated cells (bottom). Bars $=5$ and $1 \mu \mathrm{m}$.

fibroblasts compared to unlabeled peptides. However, only significant reduction in cell number was observed with the highest peptide concentration $(100 \mu \mathrm{M})$ which was not used in any of further experiments. This could be caused by the increased hydrophobicity of FITC-G3 compared to G3.

3.2. Tumour Cell Selectivity of G3 Peptide. FITC-G3 was used to investigate the tumor cell selectivity as shown in Figure 2. Both HCT-116 and HDFs were exposed for $24 \mathrm{~h}$ to the same range of concentrations of FITC-G3. Prior to fixation, samples were washed by an acid buffer to remove the peptide bond on the cellular membranes. The amount of peptide uptaken by the cells is directly proportioned to the intensity of green fluorescence observed in each image. HDFs showed very low green fluorescence intensity, while the HCT-116 showed strong green fluorescence intensity (Figure 2a,b). The internalization is concentration-dependent and when applying the highest tested concentration $(50 \mu \mathrm{M})$, the green fluorophore in HCT-116 was completely saturated. Figure $2 \mathrm{c}, \mathrm{d}$ compares the fluorescence intensity between the HCT-116 and HDF cells. The former had a much stronger intensity. A similar level of fluorescence intensity was observed before and after the acid wash, indicating that most of the peptides were inside the cells rather than on the cell membrane. SI Figure S2 shows the levels of peptide uptake at different time points (from $15 \mathrm{~min}$ to $3 \mathrm{~h}$ ) in both cancer and non-cancer cells. Clearly, the peptide showed excellent cancer cell selectivity and fast internalization into cancer cells (peptides were already internalized by the cells after $30 \mathrm{~min}$ of exposure), while no obvious fluorescence was observed in HDF cells, at any of the tested time points.

3.3. The Effect of G3 on Cancer Cells. SEM and TEM were used to better understand and visualize with detail of the HCT-116 cellular membranes and the internal peptide localization. Figure 3 shows the SEM images of the cancer cells exposed to 0 (control), $0.3,6.25$, or $100 \mu \mathrm{M}$ of FITC-G3 for 24 h. $0.3 \mu \mathrm{M}$ represented the highest peptide dose used for siRNA transfection. In normal healthy cells, the membranes are covered in a thin actin plasma membrane, protrusive structures named filopodia which are essential for sensing the nearby environment. Filopodia have a pivotal role in cell migration, adhesion morphogenesis and endocytosis, especially in cancer cells. ${ }^{31}$ They promote cellular invasion through the tumor microenvironment and are considered indispensable for driving cancer cell metastasis and proliferation. ${ }^{32}$ No evident modification was observed in cells treated with 0.3 or $6.25 \mu \mathrm{M}$ which appeared healthy with membranes enriched in filopodia, while cells treated with $100 \mu \mathrm{M}$ not only were reduced in number (as already illustrated in Figure 1) but also showed severe signs of deterioration. They also presented a complete lack of filamentous protrusions. This was even more evident at higher magnification (Figure 3b), where treated cells had a clear "spongy"-like phenotype, clearly demonstrating the cell membrane disruption. From these images, however, it is impossible to determine peptide internalization.

To further investigate the fate of the internalized peptide in cancer cells, TEM was used. To be able to localize the peptide an antibody (anti-FITC conjugated with $10 \mathrm{~nm}$ gold nanoparticles) was connected to the FITC-G3 before being incubated with the HCT-116 cancer cells at $6.25 \mu \mathrm{M}$ of FITC-G3 peptide for 3 or $24 \mathrm{~h}$. then fixed and embedded in resin. Indeed, colloidal gold nanoparticles, due to their electron density can be easily recognized on a TEM as dark spherical dots. ${ }^{33,34}$ Samples incubated with the antibody-only were considered as negative controls. Figure 4A-D shows the images of a cancer cell exposed to a solution of peptide-antibody complexes for $3 \mathrm{~h}$. The yellow circles indicate the gold nanoparticles visible as dark, electrondense spheres. The nanoparticles are found in large vesicles (red panel) or on the cell membranes (blue and green panels). Figure $4 \mathrm{E}-\mathrm{J}$ shows images of cells exposed to the same concentration of peptide for $24 \mathrm{~h}$. Many vesicles of endocytic compartments full of gold nanoparticles are visible (yellow circle). From E to G there is a cell with some superficial early endosomes (blue panel) and some compartments more internally localized (red panel) which might be late endosomes. From $\mathrm{H}$ to J, another cell was exposed to peptide/antibody complexes with clear signs of distress. The membrane structures are falling apart, while many gold nanoparticles are visible (yellow circles) in big vesicles. In contrast, images of control cells (SI Figure S3) show that both antibody and peptide are not visible in TEM images if not complexed together.

3.4. FITC-G3 Uptake Is Driven by an Energy-Dependent Process. A cold assay was performed to investigate if FITCG3 peptide uptake was driven by an energy-dependent process. The idea behind this assay is that if the temperature drops, all the metabolic active processes in the cells will stop, including the internalization of particles via endocytosis. Endocytosis is indeed an energy-dependent process that becomes strongly inhibited with a decrease in cell temperature. ${ }^{35-37}$ In the assay, cells were kept at $4{ }^{\circ} \mathrm{C}$ for $30 \mathrm{~min}$ and the peptide uptake was 

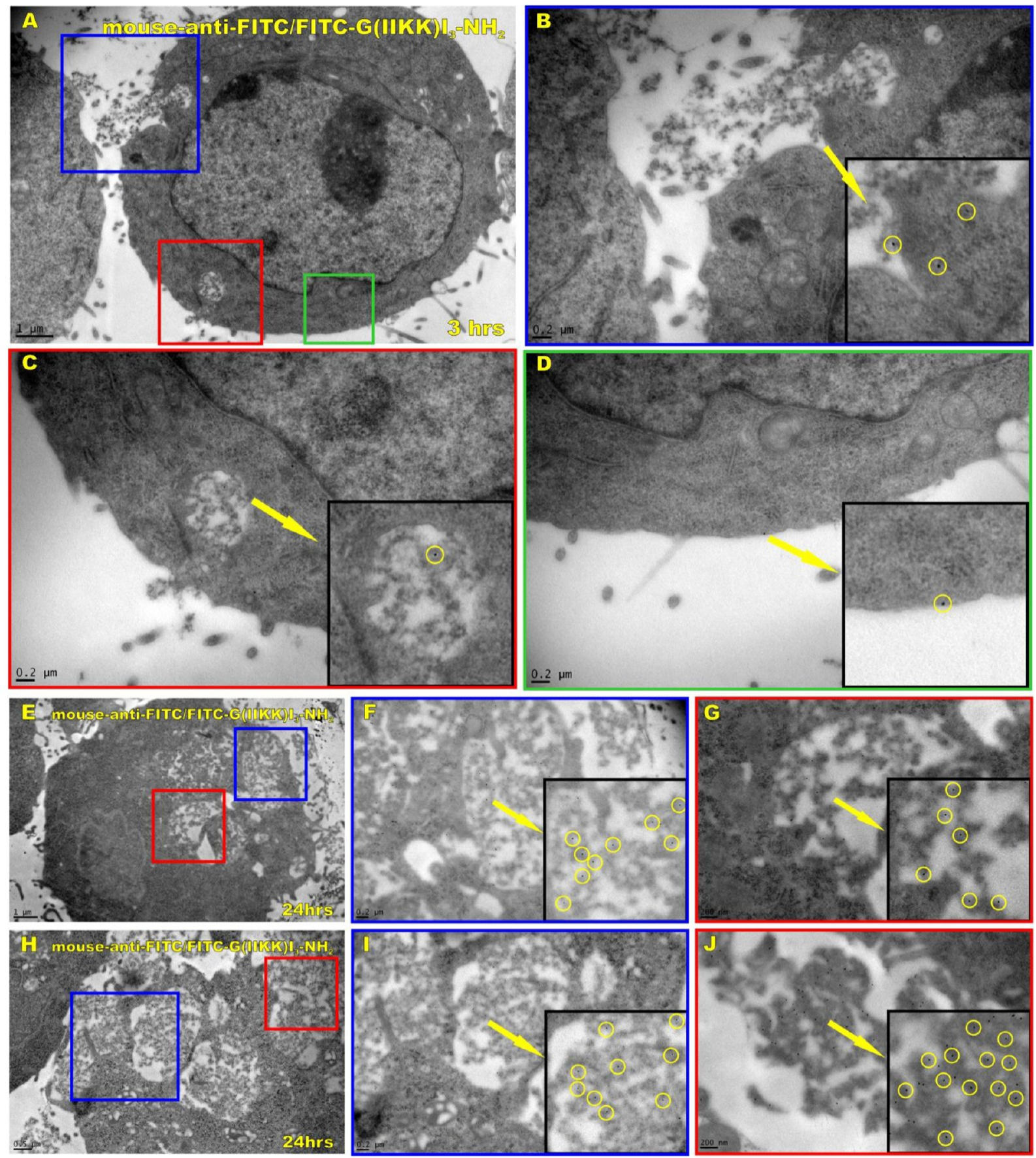

Figure 4. TEM images of cancer cells following $3 \mathrm{~h}(\mathrm{~A}-\mathrm{D})$ and $24 \mathrm{~h}(\mathrm{E}-\mathrm{J})$ exposure to complexes of FITC-G3 and anti-FITC antibody conjugated with $10 \mathrm{~nm}$ Au nanoparticles. HCT-116 cancer cells were exposed to $6.25 \mu \mathrm{M}$ of FITC-G3 complexed with a mouse monoclonal antibody anti-FITC conjugated with $10 \mathrm{~nm}$ Au nanoparticles (1/100 dilution) and then imaged using TEM. The antibody was used to label the peptide and localize it inside the cells. (A-D) TEM images show that after $3 \mathrm{~h}$ exposure a few Au nanoparticles (yellow circles) are visible in vesicles or in proximity to the plasma membrane. (E-G) TEM images show that after $24 \mathrm{~h}$ exposure many Au nanoparticles (yellow circles) were included in a big endocytic compartment, possibly endosomes. (H-J) Another cell was exposed to peptide/antibody complexes with many internalized Au nanoparticles (yellow circles); the cell is severely damaged, and the membrane is falling apart. Bars $=0.2,0.5$, or $1 \mu \mathrm{m}$. Images of cells exposed just to the peptide, or the antibody can be found in SI Figure S2.

measured as quantification of green fluorescence observed inside the cells and normalized to control of cells kept at $37^{\circ} \mathrm{C}$ for the same amount of time. Further conditions were tested, including the evaluation of the recovery of cell metabolism after the cold thermic shock and the ability of the peptide internalization. In the first case, the cells following the initial
$30 \mathrm{~min}$ at $4{ }^{\circ} \mathrm{C}$ were moved to $37^{\circ} \mathrm{C}$ for $3 \mathrm{~h}$ and then the peptide uptake was measured. In the second case, the cells were washed and replaced with medium without peptide prior to the $3 \mathrm{~h}$ period at $37^{\circ} \mathrm{C}$. In both cases, the quantification of fluorescence was normalized against a control of cells kept at $37^{\circ} \mathrm{C}$ for $3 \mathrm{~h}$. The imaging and fluorescence quantification (Figure 5) were 

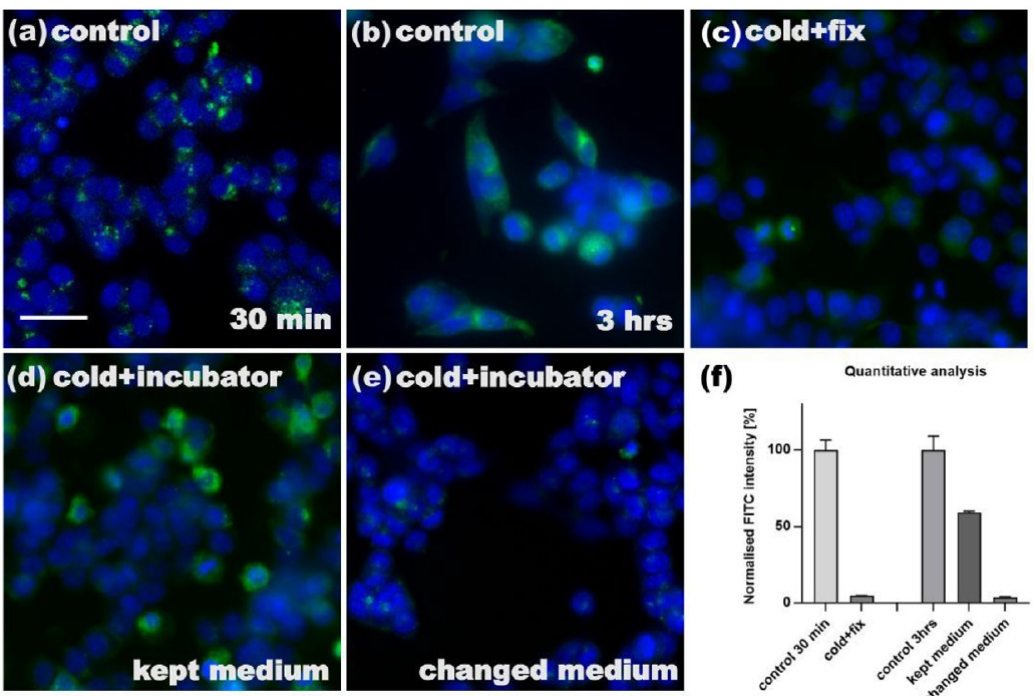

(f)

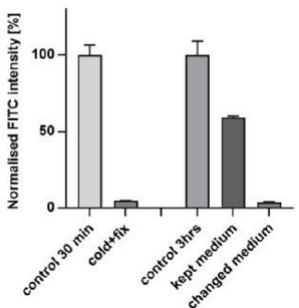

Figure 5. The peptide uptake is prevented in a cold environment. A cold assay was performed to evaluate FITC-G3 peptide uptake efficiency in cancer cells under different conditions. HCT-116 cancer cells were exposed to $12.5 \mu \mathrm{M}$ of FITC-G3 at $37^{\circ} \mathrm{C}$ for 30 min (a) and $3 \mathrm{~h}$ (b) followed by fixation (control). (c) HCT-116 cancer cells were exposed to $12.5 \mu \mathrm{M}$ of FITC-G3 for $30 \mathrm{~min}$ in a cold environment $\left(4^{\circ} \mathrm{C}\right)$ followed by fixation (cold + fix). Some cells from (c) (before fixation) were subsequently incubated for $3 \mathrm{~h}$ at $37^{\circ} \mathrm{C}$ (cold + incubation) keeping the same medium (d) or replacing the medium with a fresh one but lacking peptide (e). The graph in (f) shows the quantitative analysis performed to evaluate the level of FITC intensity observed in the experimental conditions $(\mathrm{a}-\mathrm{e})$ and normalized by the controls. The values obtained are averages of independent experiments \pm standard error mean $( \pm S E M)$. The images complemented by the graph show that the peptide is not internalized by the cells unless a warm environment is provided, suggesting that the internalization occurs mainly via an active process that requires energy to function. Bar $=25 \mu \mathrm{m}$.

performed using the IN CELL Analyzer microscope and the In Cell Developer Toolbox 1.9 software, respectively. It can be observed that in a cold environment very little peptide internalization occurs. However, if the right temperature was restored, cells can recover and once again, uptake the peptide. Strikingly, if the medium containing peptide is removed before restoring the standard culturing conditions, not much peptide gets internalized. This proved that cells require a warm environment, and therefore energy, to uptake FITC-G3. In the absence of an active energy-dependent process, the peptide alone is unable to stick to the cellular membrane and can be easily washed away.

3.5. RNAi Screens. The peptide uptake was prevented when cells were kept at $4{ }^{\circ} \mathrm{C}$, suggesting that an energy-dependent process (i.e., endocytosis) is necessary for its internalization. Therefore, we next wondered whether it was possible to identify which cellular pathway is responsible for FITC-G3 uptake. To do so, we performed an assay development screening followed by a wider RNAi high-content screening. The initial assay was essential to establish the correct experimental conditions such as cell density and concentration of transfection reagent. A siRNA library called assay development plate 2 (ASD2), specifically designed by the Sheffield RNAi Screening Facility was used. The library was predominantly composed of siRNAs targeting kinases, but a few were targeting genes related to endocytic pathways and therefore considered possible "hits" (see Table 1; for the ASD2 full gene list refers to SI Table S1). HCT-116 cells were transfected with the siRNAs for 3 days and then incubated with $6.25 \mu \mathrm{M}$ of FITC-G3 for a further $24 \mathrm{~h}$. Four different nontargeting siRNAs (On-TARGETplus nontargeting control $\# 2$, \#3, \#4, and \#5) were used as negative control and their phenotype considered the standard to be compared with. The cell density and FITC integrated intensity were subsequently quantified using the Multi-Wavelength Scoring algorithm within the MetaXpress software.
Table 1. Genes Selected from the Assay Development Plate 2 As Possible "Hits" for FITC-G3 Peptide ${ }^{a}$

\begin{tabular}{|c|c|c|}
\hline gene & ID & function \\
\hline ACTR2 & 10097 & $\begin{array}{l}\text { ATP-binding component of the Arp } 2 / 3 \text { complex involved } \\
\text { in the regulation of actin polymerization } 39\end{array}$ \\
\hline ARF6 & 382 & $\begin{array}{l}\text { GTP-binding protein involved in protein trafficking. It } \\
\text { regulates endocytic recycling and cytoskeleton } \\
\text { remodelling }\end{array}$ \\
\hline CAV1 & 857 & scaffolding protein within caveolar membranes ${ }^{40}$ \\
\hline CLTC & 1213 & $\begin{array}{l}\text { clathrin heavy chain protein. One of the components of a } \\
\text { polyhedral structure of coated pits and vesicles which } \\
\text { entrap specific macromolecules during receptor-mediated } \\
\text { endocytosis }\end{array}$ \\
\hline DNM2 & 1785 & $\begin{array}{l}\text { GTP-binding protein associated with microtubules and } \\
\text { implicated in endocytosis and cell motility }\end{array}$ \\
\hline MYO5A & 4644 & \multirow{3}{*}{$\begin{array}{l}\text { class of actin-based motor proteins involved in cargoes } \\
\text { transport endocytic vesicular trafficking and endosomes } \\
\text { recycling in neuronal and epithelial cells }{ }^{43,44}\end{array}$} \\
\hline MYO5B & 4645 & \\
\hline MYO5C & 55930 & \\
\hline RAB7A & 7879 & $\begin{array}{l}\text { the key regulator in endolysosomal trafficking and in the } \\
\text { early to-late endosomal maturation }\end{array}$ \\
\hline
\end{tabular}

The cell counting analysis revealed that, while transfections made with the nontargeting siRNAs did not interfere with the cell viability (SI Figure S4), a significant variation in cell number was observed in several of the functional siRNA (Figure 6a). A decrease in the cellular growth was encountered for Actr2, Cav1, Myo5a, and Myo5b where the number of cells was lower than the negative control. The knockdown of Cltc, Dnm2, Myo5c, and Rab7a instead did not affect the overall cell population. The quantification of internalized peptide per cell (Figure 6b,c) showed a general decrease in uptake, with the exclusion of Actr2 and Rab7a, which maintained levels comparable to the negative control, and Arf6, for which a significant increase was instead observed. Arf6 is essential for endosomal recycling in both clathrin-dependent and independent pathways ${ }^{38}$ and this latter observation could imply that not only FITC-G3 is internalized 
(a)

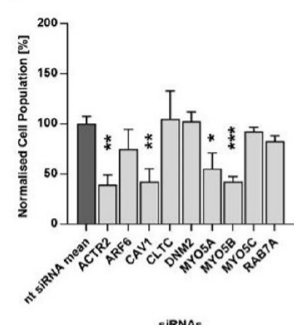

(d)

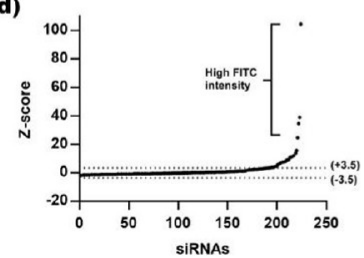

(f)

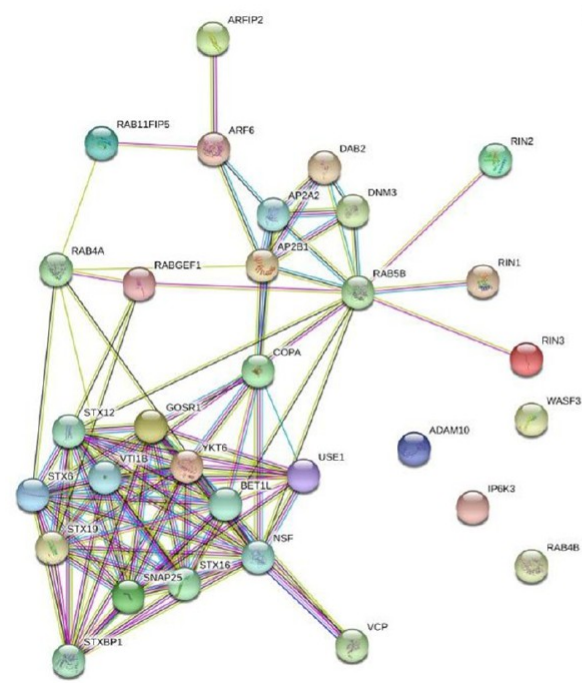

(c)

b)

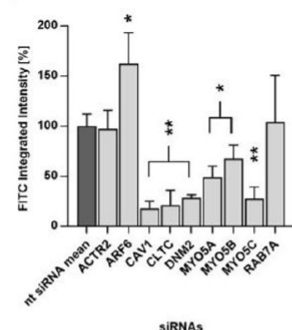

(e)
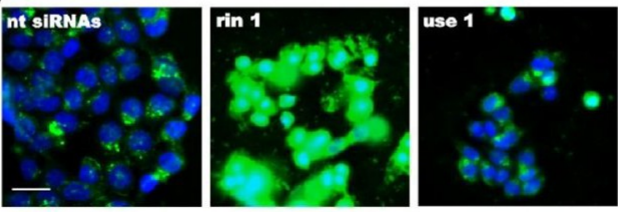

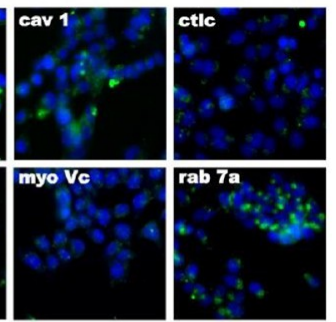

(g)

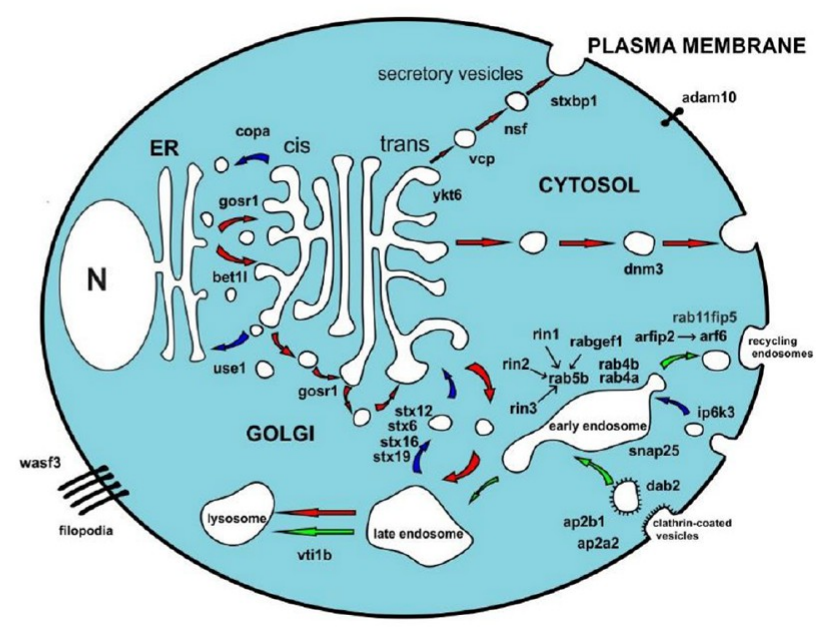

Figure 6. High-content RNAi targeted screen was performed to investigate the endocytic pathways involved in the uptake of FITC-G3 in HCT-116. $(\mathrm{a}-\mathrm{c})$ Before conducting the high-content RNAi screen, an assay development screening was performed. The cancer cells were transfected with nontargeting siRNAs or endocytosis-related siRNAs prior to exposure to $6.25 \mu \mathrm{M}$ of the fluorescent peptide. (a) Number of cells counted after RNAi knock-down, normalized to the negative control (nt), and expressed as a percentage (\%). (b) FITC fluorescence intensity per cell evaluated in HCT116 cells following RNAi knock-down, normalized to the negative control (nt) and expressed as a percentage (\%). In both graphs, the negative controls correspond to cells transfected with non-targeting (nt) siRNAs (average of 4 different siRNAs). (c) Images of the cells represented in (a,b) showing the level of peptide uptake according to the different siRNA transfection. A control image of not transfected cells but exposed to $6.25 \mu \mathrm{M}$ of the peptide is represented as well as a control. Following the same transfection procedure adopted for the assay development, an RNAi genome screen was then performed and the robust Z-score was used to normalize the data obtained. (d) Graphical representation of the RNAi screen output with the distribution of Z-scores across the whole library. (e) Images of cells in which Rin1, Use 1, Rin 2, and Copa were knocked down. The level of green FITC fluorescence intensity was much higher compared to the control (non-targeting siRNAs). (f) Schematic representation of the interactions between the hits found in the screen using String 10.5 to create an interactive map. (g) Schematic representation of the hits main functions in the cell endocytosis. Legend: $\mathrm{N}=$ nucleus; $\mathrm{ER}=$ endoplasmic reticulum. All the images are scaled at the same size. In all the images nuclei were stained with Hoechst 33342 $(2 \mu \mathrm{g} / \mathrm{mL})$. Bar $=25 \mu \mathrm{M}$. The values obtained are averages of independent experiments with at least three replicates for each experimental point \pm standard error mean $( \pm S E M)$. Statistically significant difference from the negative controls was determined by Student's $t$ test $(* p<0.05$; $* * p<0.01$; $* * * p<0.001)$.

via endocytosis, but also that, in physiological conditions, it is recycled back on the cell surface.

For the high content genome screen, a library containing more than 200 siRNAs targeting genes involved in endocytosis was used (see SI Table S2 for the complete list). The data obtained were normalized using the robust z-score method $(Z=$ $\left(X_{\mathrm{i}}\right.$-median $\left.) / \mathrm{MAD}\right)$ which uses median and median absolute deviation $(\mathrm{MAD})$ instead of mean and standard deviation. The possible hits were identified in the outliers scoring $\leq-3.5$ or $\geq$
+3.5 z-scores (Figure 6d). The identified hits were 31 (see Table $2)$; Use1, Rin2, and Copa gave very high $z$-scores compared to the rest of the distribution: 39029,34535 , and 24672 respectively (Figure 6d,e). Rin1 scored the highest, with 104479 , which is also reflected by the correspondent picture in Figure 6e. The peptide completed saturated the cytoplasm of the cells also affecting their viability. The predictive interactions between these hits have been graphically represented using STRING 10.5 database (Figure 6f). We can observe two big, 
Table 2. Complete List of the Hits in the High-Content Genome Screen, Identified As Outliers Scoring $\leq-3.5$ or $\geq$ $+3.5 z$-scores

\begin{tabular}{lcllll}
\multicolumn{1}{c}{ gene } & $z$-score & gene & z-score & \multicolumn{1}{c}{ gene } & $z$-score \\
STXBP1 & 3646 & STX19 & 7248 & VCP & 11372 \\
ARF6 & 3769 & STX12 & 7660 & RAB4B & 11836 \\
BET1L & 3838 & GAF1 & 7839 & DAB2 & 12040 \\
GOSR1 & 3969 & RAB4A & 7866 & AP2A2 & 12710 \\
NSF & 4263 & VTI1B & 8237 & AP2B1 & 13842 \\
IHPK3 & 4604 & SNAP25 & 9150 & RABGEF1 & 15778 \\
STX6 & 4844 & WASF3 & 9153 & COPA & 24672 \\
RAB5B & 5716 & ARFIP2 & 9312 & RIN2 & 34535 \\
STX16 & 6389 & DNM3 & 10880 & USE1 & 39029 \\
YKT6 & 6462 & RIN3 & 11130 & RIN1 & 104479 \\
ADAM10 & 7149 & & & & \\
\hline
\end{tabular}

interconnected clusters: one regarding endocytic recycling pathways and the other one related to vesicles transport between secretory compartments, mainly associated with the Golgi network, associated with the recycling pathways cluster we found Rin 1, Rin 2, and Rin 3. These proteins are Guanine Nucleotide Exchange Factors (GEFs) for Rab proteins and are involved in many biological functions including cell growth, differentiation and receptor mediated endocytosis. ${ }^{46}$ Moreover, components of the Rab family, the largest group of Ras superfamily of monomeric $G$ proteins which are involved in vesicle trafficking were found as hits: Rab5b, RabGEF1, Rab4a, Rab4b, and Rab11FIP5. ${ }^{47-50}$

3.6. Targeted siRNA Delivery into Cancer Cells Using FITC-G3. RNAi is a great mechanism to alter gene expression and has proven to be very successful in silencing specific genes. However, despite having potentially good therapeutic agents, siRNAs have still very little use in clinical drug development because of their inability to show cell-type-specific cytosolic delivery. ${ }^{51,52}$ Therefore, due to both its cationicity and ability to preferentially enter cancer cells, we next asked if G3 was able to bind to negatively charged molecules and transport them only into target cells. We compared the transfection efficiency of the commercial reagent DharmaFECT1 (DF1), and either the peptide G3 or its fluorescent version, FITC-G3. HCT-116 colon cancer cells and HDFs were the cell lines of choice to demonstrate G3 specificity.

Figure $7 \mathrm{a}, \mathrm{b}$ show the transfection of $75 \mathrm{nM}$ of siGLO, a red fluorescently non-targeting siRNA, via DF1 or via progressively higher charge ratios of G3. For both cell lines, DF1 had a

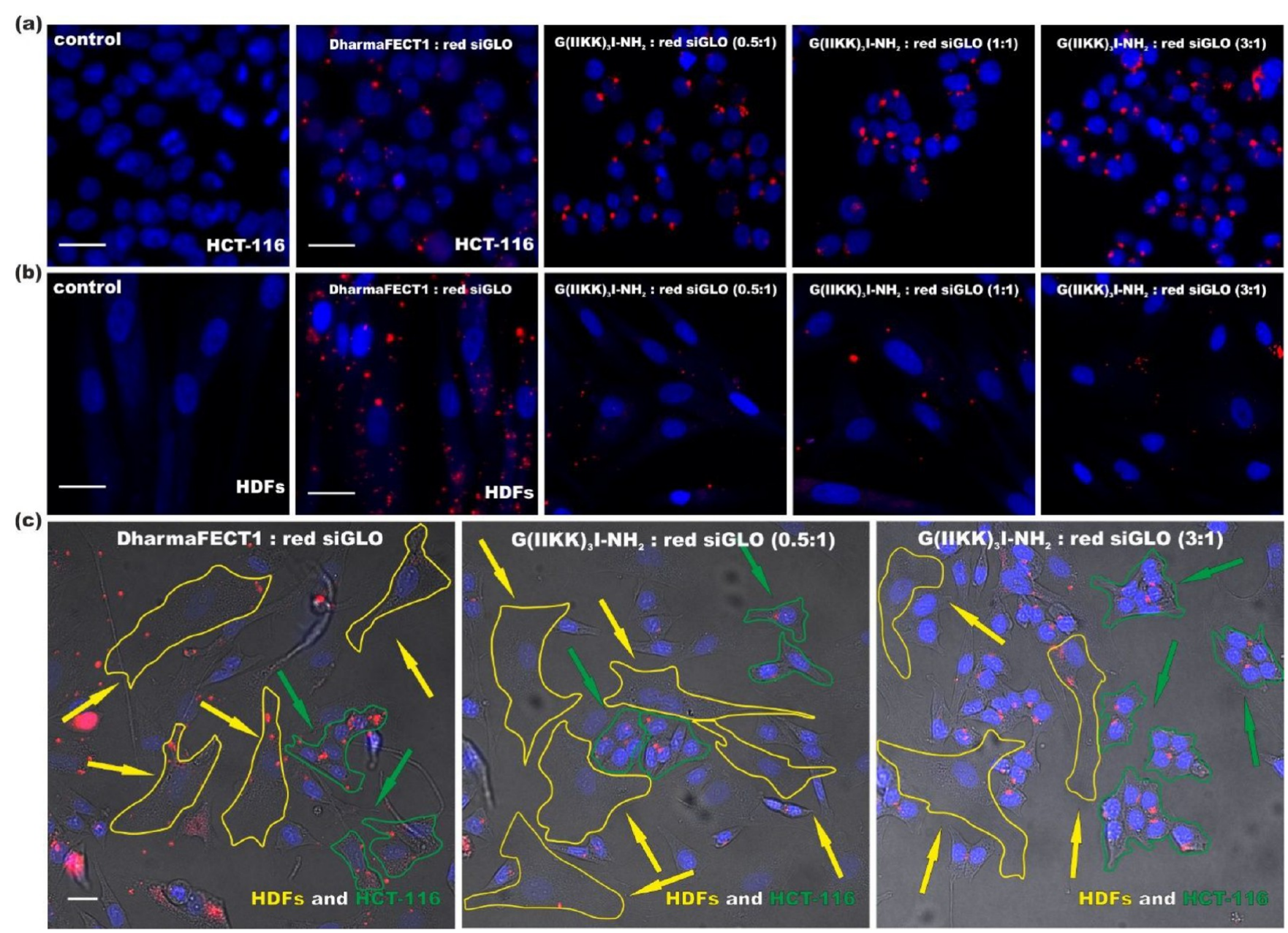

Figure 7. siRNA delivery into cancer and non-cancer cell models. HCT-116 (a) and HDFs (b) were transfected with $75 \mathrm{nM}$ of siGLO red fluorescent siRNA with increased charge ratios of G3 peptide. HCT-116 and HDFs were also cocultured (c) and transfected with $50 \mathrm{nM}$ of siGLO red using DharmaFECT1 or G3 peptide at two different ratios (0.5:1 and 3:1). In the corresponding images, yellow arrows and lines indicate the fibroblasts, while the green arrows and lines indicate the colon cancer cells. Nuclei were stained with Hoechst 33342 . Bars $=25 \mu \mathrm{m}$. 
(a)

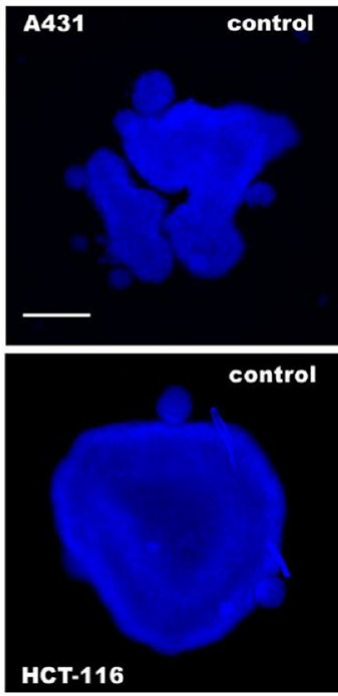

(b)

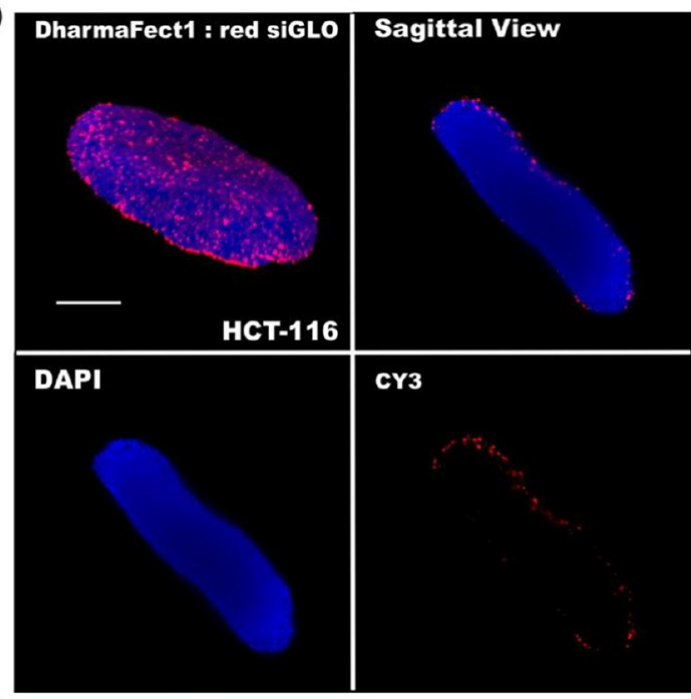

(C)

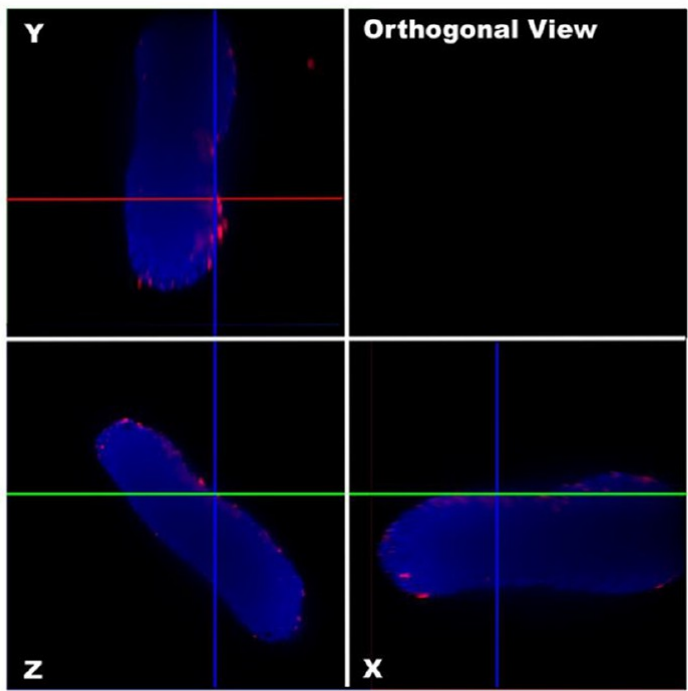

DharmaFect1 : red siGLO

A431

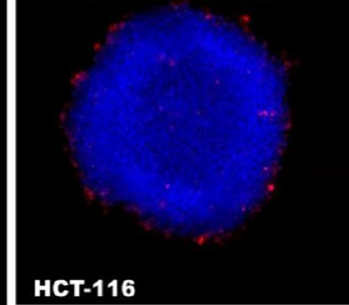

DharmaFect1 : red siGLO

HCT-116

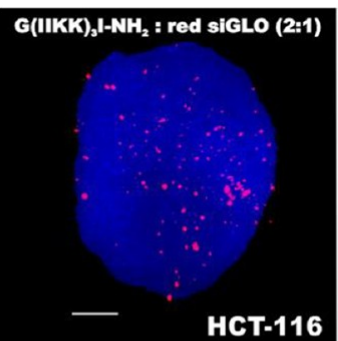

DAPI
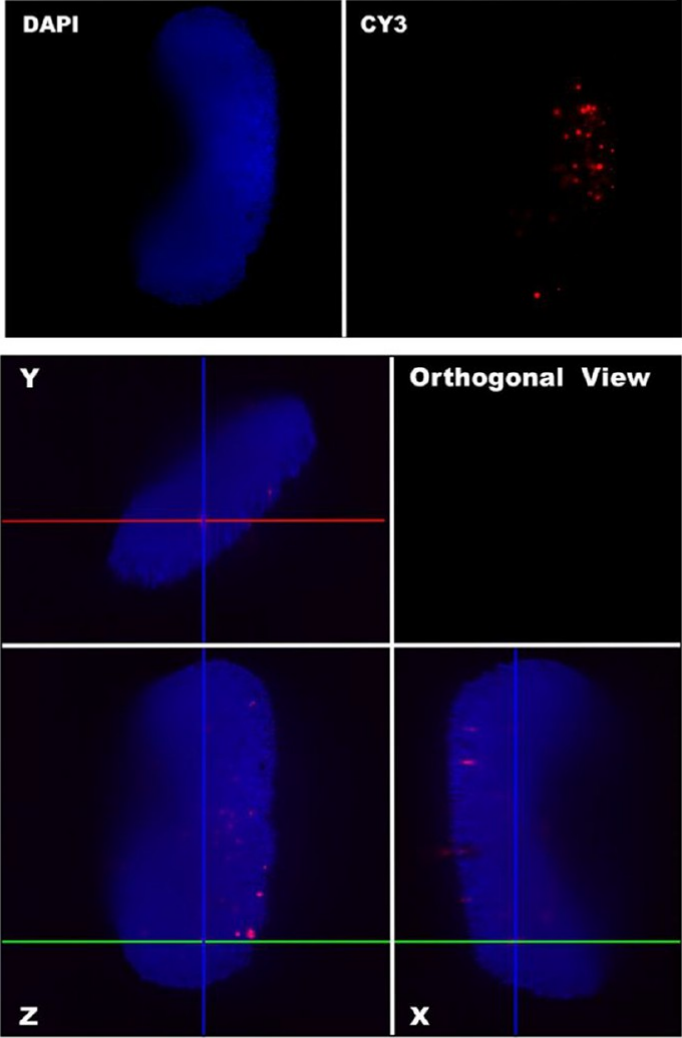

Figure 8. siRNA delivery into cancer cell spheroids. (a) Fluorescent wide-field microscope images of A431 and HCT-116 cancer cell spheroids transfected with $75 \mathrm{nM}$ of siGLO using DharmaFECT1 (positive control) or G3 peptide. (b) Images of HCT-116 spheroids transfected with $75 \mathrm{nM}$ siGLO using DharmaFECT1 or G3 peptide at 2:1 ratio and acquired using light-sheet microscopy. The first images on the top left corners are 3D reconstructions, while the others are sagittal views with combined or separated blue (DAPI) and red (cy3) fluorescent channels. (c) Orthogonal views of (b) images showing DharmaFECT1 (on the left) and G3 (on the right) transfected spheroids with the location of red siGLO puncta in $x, y, z$ planes. Nuclei were stained with Hoechst 33342. Bars $=250 \mu \mathrm{M}$. 
(a)

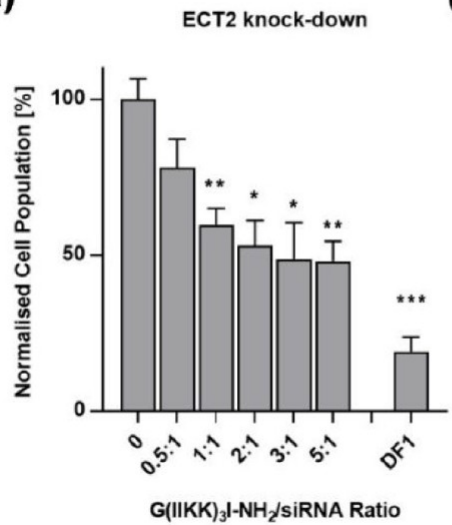

(C)

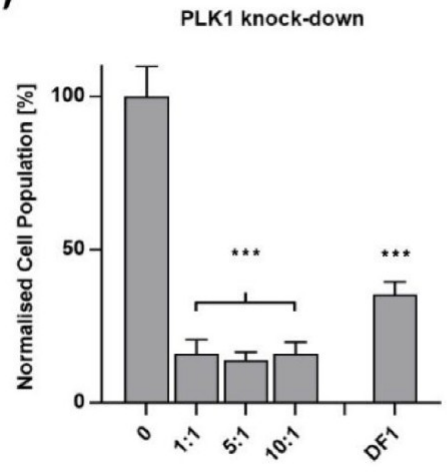

(b)
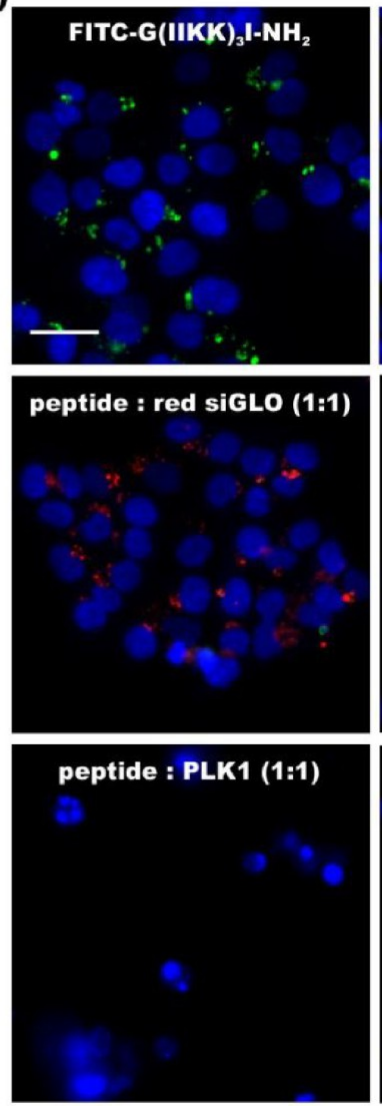
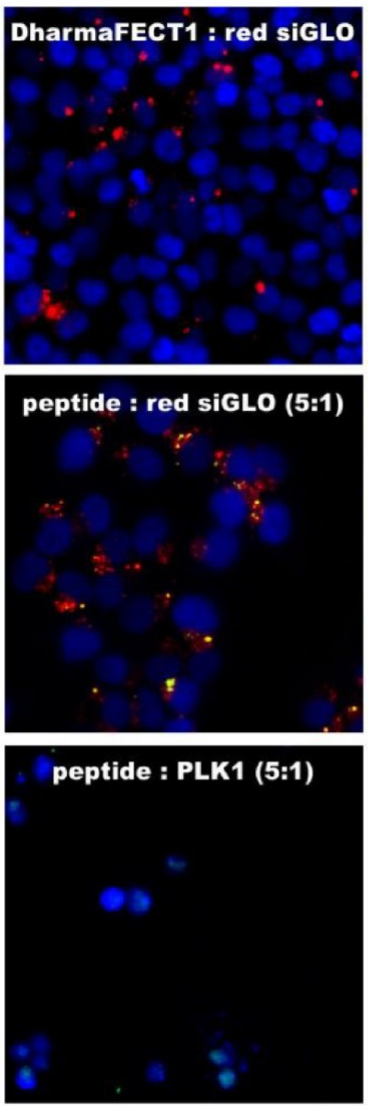
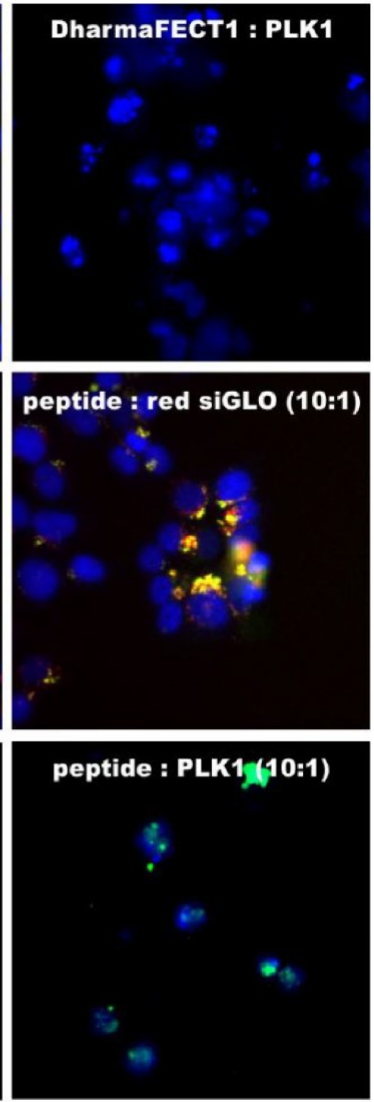

Figure 9. Gene knock-down in cancer cells. (a) Cell counting of A431 epithelial cancer cells after transfection with 30 nM of ECT2 siRNA using G3 peptide at different charge ratios (from 0.5:1 to 5:1). DharmaFECT1 was used as positive control, while the addition of siRNA only represented the negative control. (b) Images of the cells counted in and expressed in graphical form in (c) showing the effects of PLK1 siRNA successful transfection. In the top left corner, the cells were exposed to the highest concentration of peptides used to transfect the cells ( $300 \mathrm{nM}$ ). Nuclei were stained with Hoechst 33342. Bars $=25 \mu \mathrm{M}$. (c) Cell counting of HCT-116 cancer cells after transfection with $30 \mathrm{nM}$ of PLK1 siRNA using FITC-G3 peptide at different charge ratios (from 1:1 to 10:1). DharmaFECT1 was used as positive control, while transfection of red fluorescent siGLO represented the negative control. In both (a) and (c), data were normalized to the relative controls and expressed as a percentage. The values obtained are averages of independent experiments and with at least three replicates for each experimental point \pm standard error mean ( \pm SEM). Statistically significant differences from the negative controls were determined by Student's $t$ test $\left(* p<0.05 ; * *_{p}<0.01 ; * * *_{p}<0.001\right)$.

consistently high efficiency transfection level (even higher in HDFs), while the peptide showed good levels only toward the cancer cells (Figure 7a). Most of HCT-116 cells have punctate cytoplasmic fluorescence, indicating that a reasonable amount of siRNA had been internalized. However, in HDFs, it is noticeable that, at any tested ratio, only few red dots are visible (Figure $7 \mathrm{~b}$ ).

The transfection efficiency of FITC-G3 was also evaluated (SI Figure S5). Similarly, HCT-116 and HDFs were transfected using different ratios of the peptide. This time, because the peptide is FITC labeled, it was possible to observe the presence of both siRNA and peptide in the transfected cells. The yellow color of the puncta resulted from the overlap of the red (siRNA) and green (FITC) fluorescent signals. We can hypothesize that they are colocalized in the same cellular compartment. FITC-G3 behaved like its non-labeled version, showing a preference in transfecting cancer cells when compared to the HDFs. It is important to underline that all the concentrations of the peptide used for these experiments were below the toxic range identified in Figure 1, even at the highest ratios used with FITC-G3, (24:1) where $1.2 \mu \mathrm{M}$ of the peptide was complexed with $50 \mathrm{nM}$ of siRNA.

Finally, we evaluated the ability of G3 in selecting cancer cells if a more physiological environment was provided. HCT-116 and HDFs were cocultured and the cells were simultaneously transfected with $50 \mathrm{nM}$ of siGLO using DF1 or three different ratios of peptide (Figure 7c). The images shown were acquired in both fluorescent and brightfield modes and then merged to better visualize the cells and their boundaries. Yellow circles and arrows indicate the fibroblasts, while green circles and arrows are underline the cancer cells. When the transfection was made using DF1, an even distribution of siGLO among both cell types was observed, whereas, when the peptide was used instead, the siRNA was mainly found within the cancer cells. This important set of experiments confirmed that G3 has a peculiar selectivity for cancer cells which can be further exploited.

\subsection{G3 Also Delivers siRNAs into 3D Cancer Models.} Following the promising results obtained with G3 on 2D cultures, we decided to further investigate the peptide transfection efficiency in a more complex environment: a $3 \mathrm{D}$ tumor spheroid model. The ability to penetrate deeply into a solid tumor is a quality that a good carrier for either drug or gene delivery should always have. HCT-116 colon cancer cells and A431 epithelial cancer cells were cultured in ultralow attachment plates to generate spheroids and then transfected with $75 \mathrm{nM}$ of siGLO using DF1 or different peptide ratios (either 2:1 or 5:1). As a negative control, siRNA alone was added to the spheroids. 
(a)

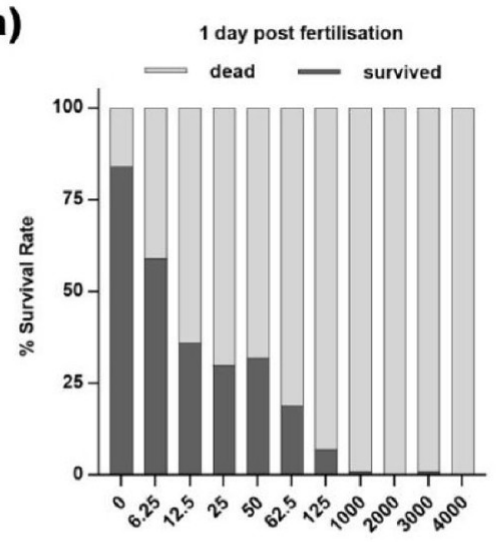

(b)

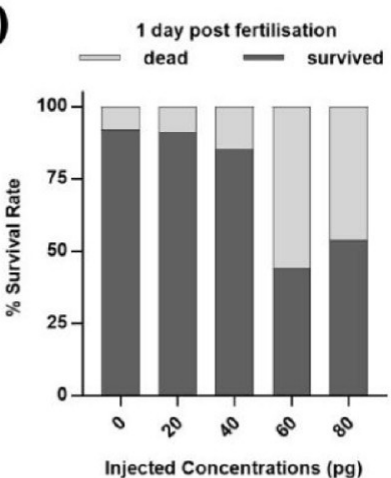

(c)

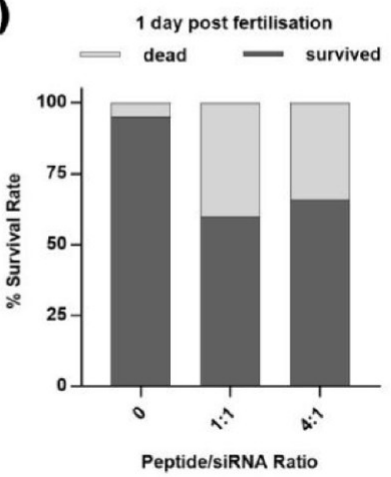

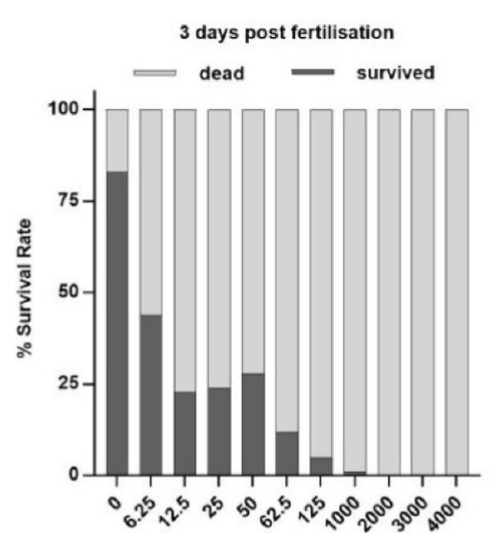

(d)
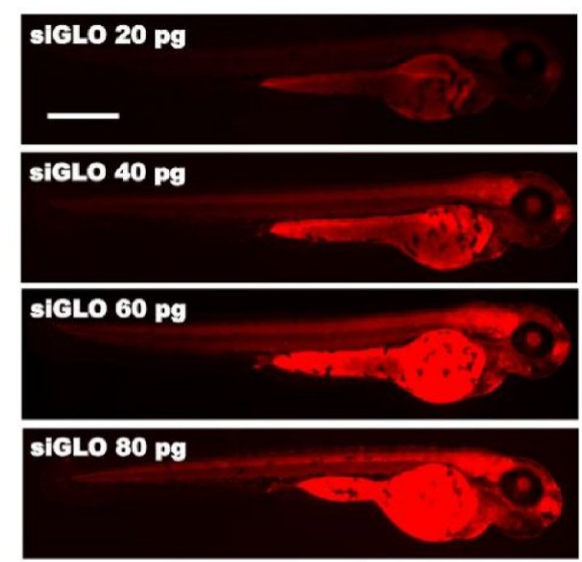

(e)
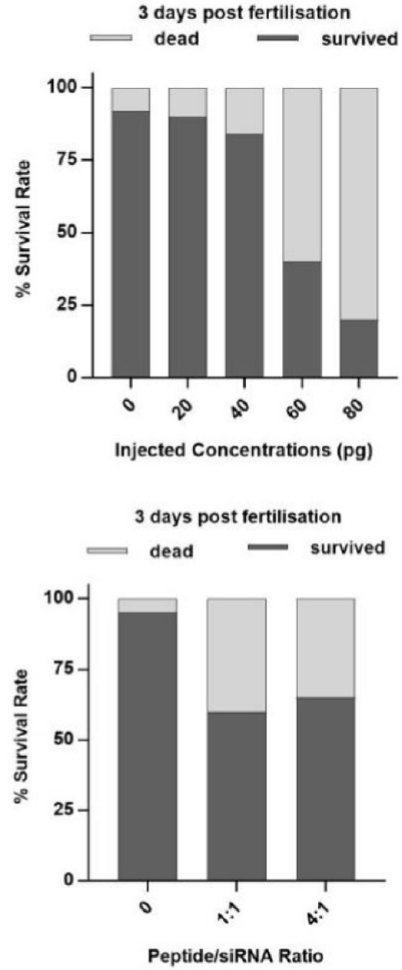

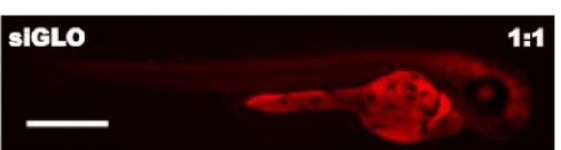

peptide
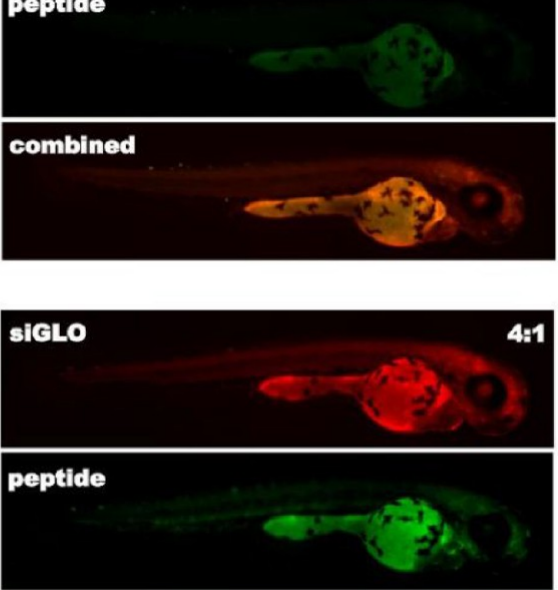

comblned

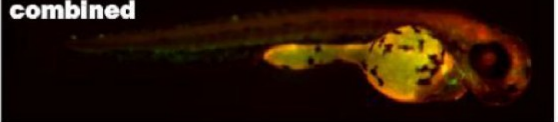

Figure 10. In vivo toxicity of the peptide and complexes using a Zebrafish model. (a) Embryos counting at 1- or 3-days post fertilization (dpf) following microinjections with FITC-G3 peptide between 6.25 and 4000 pg. (b) Embryos counting at 1- or 3-dpf following microinjections with the red fluorescent siRNA siGLO between 20 and 80 pg. (c) Embryos counting at 1- or 3-dpf following microinjections with 20 pg of siGLO complexed with FITC-G3at 1:1 or 4:1 charge ratio. The toxicity of the peptide is significantly decreased when complexed with a cargo. (d) Images acquired with a fluorescent microscope of 3-dpf embryos microinjected with increasing concentrations of siGLO showing the siRNA distribution. (e) Images of 3-dpf embryos injected with peptide/siGLO complexes showing the distribution of the fluorescent siRNA and peptide in the body of the embryo. Bars $=500$ $\mu \mathrm{M}$.

From the preliminary observation under the wide-field microscope, A431 spheroids appeared generally asymmetrical and differently sized while the ones made with HCT-116 were more compact, spherical and had an average size of $600-800 \mu \mathrm{m}$ (Figure 8a). Due to their more appropriate shape, HCT-116 spheroids were also imaged using light-sheet microscopy (Figure 8b-c). This allowed us to evaluate the depth in transfection obtained with the peptide and compare it with the commercial DF1. The clear visible difference between the images in Figure $8 \mathrm{~b}, \mathrm{c}$ is the distribution of the red siGLO across the spheroids' area. When transfection with DF1 occurred, the fluorescence of the siRNA was exclusively located on the spheroid's surface, whereas, when G3 was used, the siRNA was uniformly distributed across the whole volume of the spheroid. This could be nicely appreciated with the $3 \mathrm{D}$ reconstructions, both the sagittal and orthogonal views were elaborated with ZEN 2014 SP1 (Zeiss) software. In the orthogonal view, blue, red, and green lines, which represent respectively the $x, y, z$ planes, display the localization of single red puncta in a $3 \mathrm{D}$ spatial distribution.

3.8. Effective Cancer Genes Knock-down Using the Peptides as siRNA Carriers. Following all the promising results obtained with G3 in transfecting non-targeting siRNAs into $2 \mathrm{D}$ and $3 \mathrm{D}$ cultures of cancer cells, two functional siRNAs 
targeting ECT2 (Epithelial Cell Transforming 2 oncogene) and PLK1 (Polo-Like Kinase 1) were transfected into cancer cells. Depletion of these two genes by RNAi induces the arrest of the cell cycle and consequent apoptosis, which can be easily quantified as a decrease in cell numbers. ${ }^{53,54}$

The $30 \mathrm{nM}$ of ECT2 siRNA was transfected in A431 cells using G3 while $30 \mathrm{nM}$ of PLK1 was transfected in HCT-116 using FITC-G3. DF1 transfection performed in parallel was considered as a positive control. In the ECT2 siRNA transfection, the uncomplexed siRNAs diluted in the culture medium was used as the negative control. In the PLK1 siRNA transfection instead, the transfection of the red siGLO was considered as the negative control. In both sets of experiments, the number of cells was counted three days after transfection and then normalized to their relative negative controls. The graph in Figure 9a shows the cell number for ECT2 siRNA transfection cells using G3 at different ratios or DF1. the DF1, as expected, had a reasonable degree of knockdown $(-75 \%$ in cell population). The peptide also, apart from the smaller ratio, showed a significant decrease in cell number $(-50 \%$ in cell population) consistent with a successful RNAi. Interestingly, little difference was observed across the various ratios used after $1: 1$.

The graph in Figure 9c instead shows the cell count following transfection of PLK1 siRNA in HCT-116 using FITC-G3 or DF1. The usage of DF1 as a delivery agent significantly decreased the cell population by $65 \%$. It is worth noting that the transfection with FITC-G3 was more efficient than unlabeled G3, at every ratio, the cell number decreased by $80 \%$ compared to the control. This can be a result of a minor increase in hydrophobicity in FITC-G3 as a result of adding the FITC molecule to the peptide structure. ${ }^{55}$ Since the fluorescent siRNA and peptide were used as the negative control and delivery agent, it was possible to observe at higher magnification the presence of the peptide inside the cells at the higher ratio used (10:1 corresponding to $300 \mathrm{nM}$ ) or once again the colocalization of siGLO and peptide as yellow cytoplasmic puncta in the negative control (Figure 9b). To ensure that the concentrations of peptide used in this experiment did not impact the cell viability, the control experiment was performed using $300 \mathrm{nM}$ of peptide (first image in the top left corner). No signs of toxicity were visible, with the number of cells that showed to be $103 \%$ compared to the negative control.

3.9. In Vivo Toxicity Study. Zebrafish embryos were used as the chosen in vivo model to evaluate the toxicity of the FITC-G3 peptide. Embryos in the single-cell stage were microinjected with the peptide. Concentrations in the range of $3 \mu \mathrm{M}$ to $2 \mathrm{mM}$ (corresponding to $0.065-4 \mathrm{ng} / \mathrm{embryo}$ ) were chosen to investigate the toxicity of FITC-G3during the embryonic development of zebrafish. From Figure 10a, it was observed that all the tested concentrations, apart from 6.25 pg significantly reduced the number of alive embryos scored at 1- or 3-days post fertilization check-points. A little variation is observed between the two time points suggesting that the peptide toxicity is more severe in the initial phases of embryogenesis. It is worth highlighting that despite the evident poor viability, the concentrations used for our transfection experiments were more than 10 times lower than $6.25 \mathrm{pg}$.

The fluorescent siRNA siGLO and its complexes of FITC-G3 peptide were also injected in zebrafish embryo at the single-cell stage to evaluate the change in peptide toxicity when used as cargo carrier inside the fish. Prior to complexation, siGLO toxicity was initially evaluated in zebrafish embryos. According to literature, injections of 100 pg or more of siRNA or DNA would kill most of the embryos. ${ }^{56,57}$ For this reason, a range of siRNA concentrations between $20 \mathrm{pg}$ and 80 pg per embryo was tested. The nonfunctional siGLO siRNA was used as the peptide's cargo to investigate whether the toxicity observed in Figure $10 \mathrm{a}$ reduces or not. Figure $10 \mathrm{~b}$ shows the results obtained from the viability assay performed on 1- or 3-days post fertilization embryos. High concentrations of siGLO (60 or 80 pg) induced acute toxicity, while 20 and 40 pg of siRNA caused a very mild effect. Therefore, $20 \mathrm{pg}$ were selected as a suitable amount for complexation with FITC-G3 peptide. Figure 10d shows zebrafish embryos at 3-dpf injected with the different concentrations of siRNA. The intensity in red fluorescence can be directly related to the amount of siRNA injected.

The peptide was complexed with $20 \mathrm{pg}$ of siGLO at two different ratios (1:1 or $4: 1$, corresponding to 20 and 80 pg of peptide) and the toxicity was carefully evaluated at the usual checkpoints (1- or 3-dpf embryos). Since $20 \mathrm{pg}$ of siGLO are not inducing toxicity to the embryos we can assume that any decreased in the survival rate can be related only to the peptide. For both tested ratios, the toxicity of the peptide did not reach $50 \%$ and it appears to be stable across the two checkpoints (Figure 10c). Comparing this data to the results in Figure 10a, the complexes showed a considerable reduction in the peptide toxicity toward the zebrafish embryos. For example, $20 \mathrm{pg}$ of FITC-G3 when complexed to siGLO, resulted in an increase in the viability of the embryos by $40 \%$ (same result on day 1 and day 3 ), while a similar concentration of free peptide $(25 \mathrm{pg}$ ) caused the death of $70 \%$ of embryos at $1 \mathrm{dpf}$ which then reached $76 \%$ by the third day. With the higher amount of peptide was used in the 4:1 ratio, the difference between the complexed and free peptide toxicity was even bigger: A viability of $65 \%$ (Figure 10c) was recorded (same result for day 1 and day 3 ). While at $62.5 \mathrm{pg}$ peptide, the closest concentration of the free peptide, instead had a higher toxic effect with a decrease in viability of $80 \%$ at day 1 which then, by day 3, increased to almost $90 \%$ (Figure 10a). These results demonstrate that, when the peptide is complexed with the siRNA, its toxicity is significantly reduced, probably due to a charge neutralization effect.

\section{DISCUSSION}

Cell-penetrating peptides (CPPs) are one of the main recent developments in drug and gene delivery. Typically, short $(<30$ amino acids) CPPs can be obtained from natural proteins or by rational design and synthesis of peptide sequences to obtain desirable properties. Recent biomedical studies on hundreds of CPPs showed that these peptides can be the next generation of anticancer agents and can be utilized as vectors for gene delivery. ${ }^{58}$ The latest research demonstrated that G3 does not only have antibacterial and anticancer activity but also have cancer cell specificity. ${ }^{29}$ These unique properties make G3 a very promising peptide in cancer therapy. However, it is essential to fully understand the G3's mechanism of action and uptake pathways in cancer cells to enhance its application and improve the design of similar peptides. In addition, it is very promising that G3 can serve as a vector for small drug molecules and genetic material delivery, which has not been reported yet. In general, exerting the required anticancer effect or delivering a loaded cargo start with internalizing the peptide into the target cell. There are two main uptake mechanisms: (i) energyindependent pathways (direct penetration) and (ii) energydependent pathways (endocytosis). ${ }^{59}$ Most cellular uptake studies investigate the direct penetration which requires a 
positively charged peptide that interacts with the negatively charged cellular membrane. ${ }^{23,59}$ So far, the design and evaluation of peptides were mainly based on optimizing the peptide charges, amphipathicity, and the size of the hydrophobic/hydrophilic domain. ${ }^{10}$ These properties are involved in the destabilization of the membrane associated with peptide folding on the lipid membrane. ${ }^{2,60-63}$ For example, the selectivity of G3 to cancer cells and bacteria has been previously correlated to the composition and structure of this peptide, which consists of Gly at the $\mathrm{N}$-terminus and amidation at the Cterminus. ${ }^{19}$ Despite the conclusions drawn from previous studies, the mechanism by which the peptide enters the cells and cause an effect remains unclear. Although the peptide interaction with the cell membrane is a key factor in peptide cellular uptake, other essential factors, such as energy-dependent pathways, play an important role in peptide uptake and activity. Our work investigated the mechanism and conditions of cellular uptake from different perspectives, to have a better insight into the mechanism of peptide-assisted gene delivery and the selective anticancer activity of the peptide. In agreement with a previous study on Hela cancer cells, ${ }^{19}$ G3 exhibited concentration-dependent cell selectivity, showing a great affinity for HCT-116 colorectal cancer cells without having significant impact on normal cells (HDFs). Our results also showed that the peptide is mainly uptaken by endocytosis and not by direct penetration, when a low concentration was used $(6.25 \mu \mathrm{M})$. However, as a result of the peptide uptake, the number of filopodia in the cancer cells treated with $100 \mu \mathrm{M}$ reduced massively, with severe signs of deterioration. This can be a result of direct penetration, disruption, and unfolding in the cell membrane by the peptide which is responsible for the selective toxicity in cancer cells. These findings show that this amphiphilic peptide behaves similarly to other primary hydrophobic peptides that are usually uptaken by endocytosis at low concentration and by direct penetration at high concentration. ${ }^{61,64,65}$ It is also worth noting that the concentration threshold for direct penetration varies from one cell line to another and from one peptide to another. ${ }^{59}$ The ability of G3 in entering cancer cells utilizing two different modalities is certainly an important property that should be further studied. Identifying the biological pathways involved in cellular internalization of the peptide and the impact of the peptide concentration on the cancer cells, are important for understanding the effect of the peptide on cancer cells and for using it as a nonviral vector for the delivery of genetic materials. By performing RNAi screening, 31 genes involved in the endocytosis of G3 were identified. These hits revealed that vesicles transport and endocytic recycling pathways are part of the uptake process in cancer cells. The cationic nature of the peptide was exploited in this study to deliver negatively charged siRNAs to target cells. By evaluating the transfection efficiency of siGLO in cancer cells (HCT-116) and normal cells (HDFs) using a commercial reagent (DF1) or G3, the peptide did not only demonstrate high transfection efficiency, but also high selectivity to cancer cells while the peptide concentration was below the toxic levels $(0.3$ $\mu \mathrm{M}$ for the highest peptide: siRNA ratio). In contrast, DF1, although showed high transfection efficiency, no cancer cell specificity was observed. In 3D cell culture, G3 significantly enhanced the penetration of siGLO into HCT-116 spheroids in comparison DF1 which allows only for transfection on the outer surface of the spheroids. When targeting siRNAs (e.g., ECT2, PLK1) were used, the peptide was still able to successfully deliver both to the target cells. However, the transfection efficiency of the peptide was either lower (ECT2 to A431) or higher (PLK1 to HCT-116) than DF1 in cells. This variation in gene delivery could be associated with the differences in biological properties of the two cell lines utilized; epithelial from an epidermoid carcinoma with abnormal expression of Epidermal growth factor receptor (EGFR) and no functional copy of p53 (A431), or epithelial from a colorectal cancer with a mutation in the proto-oncogene KRAS (HCT-116). Our work opens the doors to new protocols for investigating the anticancer activity, selectivity, and efficiency in gene delivery of peptides. The previous studies correlated these properties to the molecular structure of the peptide and exclusively studied its interaction with cellular membrane. ${ }^{23,63}$ To consider this generation of short amphiphilic peptides for clinical applications, interdisciplinary work must be conducted to fully study the peptide from different angles including physical properties, transfection efficiency in different cell lines, cellular uptake mechanisms, specificity as well as its behavior in $3 \mathrm{D}$ cell culture and in vivo. Although further studies should be combined with the presented findings to obtain a complete picture about the anticancer activity of G3 and its application in gene delivery, this study bring us a step closer to the goal.

\section{CONCLUSIONS}

In summary, we have shown that the designed amphiphilic $\alpha$ helical peptide G3 not only have an anticancer effect but also can selectively transfect cancer cells and 3D spheroids with siRNA. Transfection of the siRNA ECT2 and PLK1 in A431 and HCT116 cancer cells was successful, indicating that G3 can modulate gene expression in cancer cells. We also identified, using high content RNAi screening, an energy-dependent endocytic pathway as a possible mechanism of entry of G3 into cancer cells. Finally, G3 toxicity test on zebrafish embryos gave important information on the peptide bioavailability and confirmed its potential for further in vivo studies. Overall, this work provides new insight into the usage of G3 cell-penetrating peptides as innovative therapeutics anticancer agents.

\section{ASSOCIATED CONTENT}

\section{Supporting Information}

The Supporting Information is available free of charge at https://pubs.acs.org/doi/10.1021/acsami.1c14761.

Additional data of high content cell counting assay of FITC-G3 peptide on cancer and noncancer models; tumor cell selectivity of FITC-G3 peptide; TEM images of cancer cells following 3 and $24 \mathrm{~h}$ exposure to either FITC-G3 or anti-FITC antibody conjugated with $10 \mathrm{~nm}$ $\mathrm{Au}$ nanoparticles; cell counting analysis of cells transfected with nontargeting siRNAs (as negative control); cancer cells transfected with siGLO using FITC-G3; the complete gene list of ASD2 siRNA library; the complete gene list of the Traffic-ome siRNA library (PDF)

\section{AUTHOR INFORMATION}

\section{Corresponding Authors}

Xiubo Zhao - Department of Chemical and Biological Engineering, University of Sheffield, Sheffield S1 3JD, United Kingdom; School of Pharmacy, Changzhou University, Changzhou 213164, China; (1) orcid.org/0000-0002-46202893; Email: xiubo.zhao@sheffield.ac.uk 
Stephen Brown - Department of Biomedical Science, University of Sheffield, Sheffield S10 2TN, United Kingdom;

Email: stephen.brown@sheffield.ac.uk

\section{Authors}

Silvia Cirillo - Department of Chemical and Biological Engineering, University of Sheffield, Sheffield S1 3JD, United Kingdom; Present Address: (S.C.) School of Cellular and Molecular Medicine, University of Bristol, Bristol BS8 1TD, United Kingdom

Mhd Anas Tomeh - Department of Chemical and Biological Engineering, University of Sheffield, Sheffield S1 3JD, United Kingdom

Robert N Wilkinson - Department of Infection, Immunity \& Cardiovascular Disease, University of Sheffield, Sheffield S10 2RX, United Kingdom

Chris Hill - Department of Biomedical Science, University of Sheffield, Sheffield S10 2TN, United Kingdom

Complete contact information is available at:

https://pubs.acs.org/10.1021/acsami.1c14761

\section{Notes}

The authors declare no competing financial interest.

\section{ACKNOWLEDGMENTS}

We thank the EPSRC (EP/N007174/1 and EP/N023579/1) and Royal Society (RG160662 and IE150457) for support.

\section{REFERENCES}

(1) Partridge, A. H.; Burstein, H. J.; Winer, E. P. Side Effects of Chemotherapy and Combined Chemohormonal Therapy in Women With Early-Stage Breast Cancer. J. Natl. Cancer Inst. Monogr. 2001, 2001 (30), 135-142.

(2) Bentzen, S. M. Preventing or reducing late side effects of radiation therapy: radiobiology meets molecular pathology. Nat. Rev. Cancer 2006, 6 (9), 702-713.

(3) Torchilin, V. Intracellular delivery of protein and peptide therapeutics. Drug Discovery Today: Technol. 2008, 5 (2), No. e95-e103.

(4) Cho, K.; Wang, X.; Nie, S.; Chen, Z.; Shin, D. M. Therapeutic Nanoparticles for Drug Delivery in Cancer. Clin. Cancer Res. 2008, 14 (5), 1310-1316.

(5) Husain, S. R.; Han, J.; Au, P.; Shannon, K.; Puri, R. K. Gene therapy for cancer: regulatory considerations for approval. Cancer Gene Ther. 2015, 22 (12), 554-563.

(6) Temsamani, J.; Vidal, P. The use of cell-penetrating peptides for drug delivery. Drug Discovery Today 2004, 9 (23), 1012-1019.

(7) Wang, J.; Lu, Z.; Wientjes, M. G.; Au, J. L. S. Delivery of siRNA Therapeutics: Barriers and Carriers. AAPS J. 2010, 12 (4), 492-503.

(8) Veiman, K.-L.; Künnapuu, K.; Lehto, T.; Kiisholts, K.; Pärn, K.; Langel, Ü.; Kurrikoff, K. PEG shielded MMP sensitive CPPs for efficient and tumor specific gene delivery in vivo. J. Controlled Release 2015, 209, 238-247.

(9) Tomeh, M. A.; Hadianamrei, R.; Sun, W.; Xu, D.; Brown, S.; Zhao, X. Stiffness-tuneable nanocarriers for controlled delivery of ASC-J9 into colorectal cancer cells. J. Colloid Interface Sci. 2021, 594, 513-521.

(10) Gaspar, D.; Veiga, A. S.; Castanho, M. A. R. B. From antimicrobial to anticancer peptides. A review. Front. Microbiol. 2013, 4, 294.

(11) Li, X.; Shen, B.; Chen, Q.; Zhang, X.; Ye, Y.; Wang, F.; Zhang, X. Antitumor effects of cecropin B-LHRH' on drug-resistant ovarian and endometrial cancer cells. BMC Cancer 2016, 16, 251.

(12) Hancock, R. E. W.; Sahl, H.-G. Antimicrobial and host-defense peptides as new anti-infective therapeutic strategies. Nat. Biotechnol. 2006, 24 (12), 1551-1557.
(13) Brogden, K. A. Antimicrobial peptides: pore formers or metabolic inhibitors in bacteria? Nat. Rev. Microbiol. 2005, 3 (3), 238-250.

(14) Takahashi, D.; Shukla, S. K.; Prakash, O.; Zhang, G. Structural determinants of host defense peptides for antimicrobial activity and target cell selectivity. Biochimie 2010, 92 (9), 1236-1241.

(15) Ciumac, D.; Gong, H.; Hu, X.; Lu, J. R. Membrane targeting cationic antimicrobial peptides. J. Colloid Interface Sci. 2019, 537, 163185

(16) Nguyen, L. T.; Haney, E. F.; Vogel, H. J., The expanding scope of antimicrobial peptide structures and their modes of action. Trends Biotechnol. 2011, 29, 464-472.

(17) Schweizer, F. Cationic amphiphilic peptides with cancer-selective toxicity. Eur. J. Pharmacol. 2009, 625 (1-3), 190-194.

(18) Dissanayake, S.; Denny, W. A.; Gamage, S.; Sarojini, V. Recent developments in anticancer drug delivery using cell penetrating and tumor targeting peptides. J. Controlled Release 2017, 250, 62-76.

(19) Hu, J.; Chen, C.; Zhang, S.; Zhao, X.; Xu, H.; Zhao, X.; Lu, J. R. Designed Antimicrobial and Antitumor Peptides with High Selectivity. Biomacromolecules 2011, 12 (11), 3839-3843.

(20) Gong, H.; Zhang, J.; Hu, X.; Li, Z.; Fa, K.; Liu, H.; Waigh, T. A.; McBain, A.; Lu, J. R. Hydrophobic Control of the Bioactivity and Cytotoxicity of de Novo-Designed Antimicrobial Peptides. ACS Appl. Mater. Interfaces 2019, 11 (38), 34609-34620.

(21) Gong, H.; Liao, M.; Hu, X.; Fa, K.; Phanphak, S.; Ciumac, D.; Hollowell, P.; Shen, K.; Clifton, L. A.; Campana, M.; Webster, J. R. P.; Fragneto, G.; Waigh, T. A.; McBain, A. J.; Lu, J. R. Aggregated Amphiphilic Antimicrobial Peptides Embedded in Bacterial Membranes. ACS Appl. Mater. Interfaces 2020, 12 (40), 44420-44432.

(22) Chen, C.; Chen, Y.; Yang, C.; Zeng, P.; Xu, H.; Pan, F.; Lu, J. R. High Selective Performance of Designed Antibacterial and Anticancer Peptide Amphiphiles. ACS Appl. Mater. Interfaces 2015, 7 (31), 1734617355.

(23) Chen, C.; Hu, J.; Zeng, P.; Pan, F.; Yaseen, M.; Xu, H.; Lu, J. R. Molecular mechanisms of anticancer action and cell selectivity of short $\alpha$-helical peptides. Biomaterials 2014, 35 (5), 1552-1561.

(24) Chen, C.; Pan, F.; Zhang, S.; Hu, J.; Cao, M.; Wang, J.; Xu, H.; Zhao, X.; Lu, J. R. Antibacterial Activities of Short Designer Peptides: a Link between Propensity for Nanostructuring and Capacity for Membrane Destabilization. Biomacromolecules 2010, 11 (2), 402-411.

(25) Chen, C.; Hu, J.; Zhang, S.; Zhou, P.; Zhao, X.; Xu, H.; Zhao, X.; Yaseen, M.; Lu, J. R. Molecular mechanisms of antibacterial and antitumor actions of designed surfactant-like peptides. Biomaterials 2012, 33 (2), 592-603.

(26) Xu, H.; Wang, J.; Han, S.; Wang, J.; Yu, D.; Zhang, H.; Xia, D.; Zhao, X.; Waigh, T. A.; Lu, J. R. Hydrophobic-Region-Induced Transitions in Self-Assembled Peptide Nanostructures. Langmuir 2009, 25 (7), 4115-4123.

(27) Hu, J.; Chen, C.; Zhang, S.; Zhao, X.; Xu, H.; Zhao, X.; Lu, J. R. Designed Antimicrobial and Antitumor Peptides with High Selectivity. Biomacromolecules 2011, 12, 3839-3843.

(28) Chen, C.; Yang, C.; Chen, Y.; Wang, F.; Mu, Q.; Zhang, J.; Li, Z.; Pan, F.; Xu, H.; Lu, J. R. Surface Physical Activity and Hydrophobicity of Designed Helical Peptide Amphiphiles Control Their Bioactivity and Cell Selectivity. ACS Appl. Mater. Interfaces 2016, 8 (40), 2650126510.

(29) Chen, C.; Hu, J.; Zeng, P.; Pan, F.; Yaseen, M.; Xu, H.; Lu, J. R. Molecular mechanisms of anticancer action and cell selectivity of short alpha-helical peptides. Biomaterials 2014, 35 (5), 1552-61.

(30) Sylvester, P. W., Optimization of the Tetrazolium Dye (MTT) Colorimetric Assay for Cellular Growth and Viability. In Drug Design and Discovery: Methods and Protocols; Satyanarayanajois, S. D., Ed.; Humana Press: Totowa, NJ, 2011; pp 157-168.

(31) Mattila, P. K.; Lappalainen, P. Filopodia: molecular architecture and cellular functions. Nat. Rev. Mol. Cell Biol. 2008, 9 (6), 446-454.

(32) Jacquemet, G.; Hamidi, H.; Ivaska, J. Filopodia in cell adhesion, 3D migration and cancer cell invasion. Curr. Opin. Cell Biol. 2015, 36, $23-31$. 
(33) Goldberg, M. W.; Fiserova, J., Immunogold Labelling for Scanning Electron Microscopy. In Immunoelectron Microscopy: Methods and Protocols; Schwartzbach, S. D.; Osafune, T., Eds.; Humana Press: loc, NJ, 2010; pp 297-313.

(34) Sirerol-Piquer, M. S.; Cebrián-Silla, A.; Alfaro-Cervelló, C.; Gomez-Pinedo, U.; Soriano-Navarro, M.; Verdugo, J.-M. G. GFP immunogold staining, from light to electron microscopy, in mammalian cells. Micron 2012, 43 (5), 589-599.

(35) Hong, G.; Wu, J. Z.; Robinson, J. T.; Wang, H.; Zhang, B.; Dai, H. Three-dimensional imaging of single nanotube molecule endocytosis on plasmonic substrates. Nat. Commun. 2012, 3, 700.

(36) Tomoda, H.; Kishimoto, Y.; Lee, Y. C. Temperature effect on endocytosis and exocytosis by rabbit alveolar macrophages. J. Biol. Chem. 1989, 264 (26), 15445-50.

(37) Perumal, O. P.; Inapagolla, R.; Kannan, S.; Kannan, R. M. The effect of surface functionality on cellular trafficking of dendrimers. Biomaterials 2008, 29 (24), 3469-3476.

(38) Donaldson, J. G. Multiple Roles for Arf6: Sorting, Structuring, and Signaling at the Plasma Membrane. J. Biol. Chem. 2003, 278 (43), 41573-41576.

(39) Goley, E. D.; Welch, M. D. The ARP2/3 complex: an actin nucleator comes of age. Nat. Rev. Mol. Cell Biol. 2006, 7 (10), 713-726.

(40) Liu, P.; Rudick, M.; Anderson, R. G. W. Multiple Functions of Caveolin-1. J. Biol. Chem. 2002, 277 (44), 41295-41298.

(41) Royle, S. J. The cellular functions of clathrin. Cell. Mol. Life Sci. 2006, 63 (16), 1823-1832.

(42) Ferguson, S. M.; De Camilli, P. Dynamin, a membraneremodelling GTPase. Nat. Rev. Mol. Cell Biol. 2012, 13 (2), 75-88.

(43) Trybus, K. M. Myosin V from head to tail. Cell. Mol. Life Sci. 2008, 65 (9), 1378-1389.

(44) Lapierre, L. A.; Kumar, R; Hales, C. M.; Navarre, J.; Bhartur, S. G.; Burnette, J. O.; Provance, D. W.; Mercer, J. A.; Bähler, M.; Goldenring, J. R. Myosin $\mathrm{Vb}$ Is Associated with Plasma Membrane Recycling Systems. Mol. Biol. Cell 2001, 12 (6), 1843-1857.

(45) Zhang, M.; Chen, L.; Wang, S.; Wang, T. Rab7: roles in membrane trafficking and disease. Biosci. Rep. 2009, 29 (3), 193-209.

(46) Woller, B.; Luiskandl, S.; Popovic, M.; Prieler, B. E. M.; Ikonge, G.; Mutzl, M.; Rehmann, H.; Herbst, R. Rin-like, a novel regulator of endocytosis, acts as guanine nucleotide exchange factor for Rab5a and Rab22. Biochim. Biophys. Acta, Mol. Cell Res. 2011, 1813 (6), 11981210.

(47) Bucci, C.; Parton, R. G.; Mather, I. H.; Stunnenberg, H.; Simons, K.; Hoflack, B.; Zerial, M. The small GTPase rab5 functions as a regulatory factor in the early endocytic pathway. Cell 1992, 70 (5), $715-728$.

(48) Yudowski, G. A.; Puthenveedu, M. A.; Henry, A. G.; von Zastrow, M. Cargo-Mediated Regulation of a Rapid Rab4-Dependent Recycling Pathway. Mol. Biol. Cell 2009, 20 (11), 2774-2784.

(49) Perrin, L.; Lacas-Gervais, S.; Gilleron, J.; Ceppo, F.; Prodon, F.; Benmerah, A.; Tanti, J.-F.; Cormont, M. Rab4b controls an early endosome sorting event by interacting with the $\gamma$-subunit of the clathrin adaptor complex 1. J. Cell Sci. 2013, 126 (21), 4950-4962.

(50) Schonteich, E.; Wilson, G. M.; Burden, J.; Hopkins, C. R.; Anderson, K.; Goldenring, J. R.; Prekeris, R. The Rip11/Rab11-FIP5 and kinesin II complex regulates endocytic protein recycling. J. Cell Sci. 2008, 121 (22), 3824-3833.

(51) Tai, W.; Gao, X. Functional peptides for siRNA delivery. Adv. Drug Delivery Rev. 2017, 110-111, 157-168.

(52) Setten, R. L.; Rossi, J. J.; Han, S.-p. The current state and future directions of RNAi-based therapeutics. Nat. Rev. Drug Discovery 2019, 18 (6), 421-446.

(53) van der Meer, R.; Song, H. Y.; Park, S.-H.; Abdulkadir, S. A.; Roh, M. RNAi screen identifies a synthetic lethal interaction between PIM1 overexpression and PLK1 inhibition. Clin. Cancer Res. 2014, 20 (12), $3211-3221$.

(54) Xie, J.; Lei, P.; Hu, Y. Small interfering RNA-induced inhibition of epithelial cell transforming sequence 2 suppresses the proliferation, migration and invasion of osteosarcoma cells. Exp. Ther. Med. 2015, 9 (5), 1881-1886.
(55) Park, J. H.; Kwon, S.; Nam, J.-O.; Park, R.-W.; Chung, H.; Seo, S. B.; Kim, I.-S.; Kwon, I. C.; Jeong, S. Y. Self-assembled nanoparticles based on glycol chitosan bearing $5 \beta$-cholanic acid for RGD peptide delivery. J. Controlled Release 2004, 95 (3), 579-588.

(56) Bill, B. R.; Petzold, A. M.; Clark, K. J.; Schimmenti, L. A.; Ekker, S. C. A Primer for Morpholino Use in Zebrafish. Zebrafish 2009, 6 (1), 69-77.

(57) Oates, A. C.; Bruce, A. E. E.; Ho, R. K. Too Much Interference: Injection of Double-Stranded RNA Has Nonspecific Effects in the Zebrafish Embryo. Dev. Biol. 2000, 224 (1), 20-28.

(58) Taylor, R. E.; Zahid, M., Cell Penetrating Peptides, Novel Vectors for Gene Therapy. Pharmaceutics 2020, 12 (3).225

(59) Madani, F.; Lindberg, S.; Langel, U.; Futaki, S.; Graslund, A. Mechanisms of cellular uptake of cell-penetrating peptides. J. Biophys. 2011, 2011, 414729.

(60) Thorén, P. E. G.; Persson, D.; Isakson, P.; Goksör, M.; Önfelt, A.; Nordén, B. Uptake of analogs of penetratin, Tat $(48-60)$ and oligoarginine in live cells. Biochem. Biophys. Res. Commun. 2003, 307 (1), 100-107.

(61) Wadia, J. S.; Stan, R. V.; Dowdy, S. F. Transducible TAT-HA fusogenic peptide enhances escape of TAT-fusion proteins after lipid raft macropinocytosis. Nat. Med. 2004, 10 (3), 310-315.

(62) Rothbard, J. B.; Jessop, T. C.; Lewis, R. S.; Murray, B. A.; Wender, P. A. Role of membrane potential and hydrogen bonding in the mechanism of translocation of guanidinium-rich peptides into cells. J. Am. Chem. Soc. 2004, 126 (31), 9506-9507.

(63) Chen, C.; Yang, C.; Chen, Y.; Wang, F.; Mu, Q.; Zhang, J.; Li, Z.; Pan, F.; Xu, H.; Lu, J. R. Surface physical activity and hydrophobicity of designed helical peptide amphiphiles control their bioactivity and cell selectivity. ACS Appl. Mater. Interfaces 2016, 8 (40), 26501-26510.

(64) Ziegler, A. Thermodynamic studies and binding mechanisms of cell-penetrating peptides with lipids and glycosaminoglycans. Adv. Drug Delivery Rev. 2008, 60 (4), 580-597.

(65) Richard, J. P.; Melikov, K.; Vives, E.; Ramos, C.; Verbeure, B.; Gait, M. J.; Chernomordik, L. V.; Lebleu, B. Cell-penetrating peptides. A reevaluation of the mechanism of cellular uptake. J. Biol. Chem. 2003, 278 (1), 585-90. 